\title{
A third-order nonlinear optical single crystal of 3,4-dimethoxy-substituted chalcone derivative with high laser damage threshold value: a potential material for optical power limiting
}

\author{
Vinay Parol ${ }^{1} \cdot$ A. N. Prabhu ${ }^{1} \cdot$ Md Abu Taher $^{2} \cdot$ Sri Ram G. Naraharisetty $^{2} \cdot$ N. K. Lokanath ${ }^{3} \cdot$ V. Upadhyaya $^{1,4}$
}

Received: 13 February 2020 / Accepted: 18 April 2020 / Published online: 30 April 2020

(c) The Author(s) 2020

\begin{abstract}
Third-order nonlinear optical material 4-[(1E)-3-(3,4-dimethoxyphenyl)-3-oxoprop-1-en-1-yl]phenyl 4-methylbenzene-1-sulfonate (DMPMS) is crystallized by slow solvent evaporation technique. The crystal has inversion symmetry and belongs to monoclinic system with $P 2_{1} / c$ space group. The $\mathrm{C}-\mathrm{H} \cdots \mathrm{O} / \mathrm{C}-\mathrm{H} \cdots \pi$ intermolecular interactions will be large complementarity for molecular density/crystal packing. A comprehensive investigation for absorbance and emission properties has been performed. Thermal stability is up to $258{ }^{\circ} \mathrm{C}$ without any weight loss and calculated value of laser damage threshold is $\approx 12 \mathrm{GW} / \mathrm{cm}^{2}$. The DMPMS shows low dielectric constant value, about 4.42 at $1 \mathrm{MHz}$ and electronic polarizability values in the order of $10^{-23} \mathrm{~cm}^{3}$. Furthermore, theoretical calculation has been performed using B3LYP and M06-2X functional. The static first-order hyperpolarizability parameter is 55 (B3LYP) and 34 (M06-2X) times that of urea. The total contribution of second-order hyperpolarizability is $-37.9 \times 10^{-40} \mathrm{esu}$ (in B3LYP functional) and $-25.77 \times 10^{-40}$ esu (in M06-2X functional), respectively. Here, two-photon absorption mechanism is responsible for nonlinear absorption and co-efficient is found to be $28.3 \times 10^{-12} \mathrm{~m} / \mathrm{W}$. In optical limiting study, limiting threshold is found to be $65 \mu \mathrm{J}$. The real and imaginary third-order nonlinear optical susceptibility is of the order $10^{-12}$ esu.
\end{abstract}

\section{Introduction}

The organic nonlinear optical materials with high optical nonlinearity, which involve two-photon absorption mechanism, are in high demand from the point of applications such as optical switching, optical bistability, optical limiting, optical telecommunication, optical computing, higher harmonic generation and so on [1-8]. Organic molecular-based crystals are such materials which can exhibit fluorescence

V. Upadhyaya

v.upadhyaya@manipal.edu

1 Department of Physics, Manipal Institute of Technology, Manipal Academy of Higher Education, Manipal 576104, India

2 School of Physics, University of Hyderabad, Hyderabad 500046, India

3 Department of Studies in Physics, University of Mysore, Manasagangotri, Mysuru 570006, India

4 Manipal Centre for Natural Sciences, Manipal Academy of Higher Education, Manipal 576104, India emission in the blue and green region, and can find application in multicolor display and optical memories $[9,10]$. Among the organic materials, chalcone derivatives are the subclass of flavonoids with overlapping of $\pi$ orbitals and hence chalcones have high electronic mobility and electronic density [11]. From the perspective of nonlinear optical susceptibility and two-photon absorption, several research groups have used computational study for the selection NLO material by optimizing the structures [12-14]. In recent years, many researchers have reported to enhance the material property such as laser damage threshold value, ultrafast response time, high thermal stability, good nonlinear optical response and so on [15-18]. With this requirement, Raghavendra et al. reported on 3,4-dimethoxy (ketone group) [19] and 2,4,5-trimethoxy (aldehyde group) [20] chalcone-derivative single crystals. It is noted that 3,4-dimethoxy material shows reasonably high nonlinear optical absorption coefficient value as compared to 2,4,5-trimethoxy chalcone derivative. Similarly, Patil et al. [21] carried out the study by considering 4-methoxy (ketone group) and 3,4-dimethoxy (aldehyde group). In their observations, the material 
(DMMC) shows good nonlinear optical response (at $800 \mathrm{~nm}$ ) and excellent optical limiting behavior.

Among the donor electrons, the best donor electrons are from $-\mathrm{CH}_{3},-\mathrm{Br},-\mathrm{OCH}_{3}$ and $-\mathrm{Cl}$ group for molecular design to enhance nonlinear optical susceptibility reported by Zhao et al. [22]. The molecular design is a crucial part for selection of nonlinear optical material and deeper understanding is necessary from the judicious choice with the strong donor/ acceptor electrons. In our earlier report, chlorothiophene (4TPMS)- [23] and 4-methoxy (4MPMS) [24]-substituted chalcone derivatives have been reported. Both 4TPMS and 4MPMS molecules are designed in such manner that both the ends contain donor electrons and at the center it has electron-withdrawing group, where charge transfer takes place through $\pi$-conjugation bridge. At molecular level, both the molecules are assumed to have $\mathrm{D}-\pi-\mathrm{A}-\pi-\mathrm{D}$ system. Using the same strategy, molecule DMPMS is designed to have the methoxy group in the para position and another methoxy group in the meta position. The methoxy groups in meta and para positions of the aromatic ring result in increase of the electron-donating ability, as a result of which the charge flow across the molecule gets extended. The elongated $\pi$-conjugation molecules have the absorbance peak in the shorter wavelength [25]. Thus, DMPMS belongs to elongated $\pi$-conjugation system as compared to 4TPMS and 4MPMS. It is noteworthy that 4TPMS and 4MPMS show good third-order nonlinear optical response and excellent optical limiting behavior but 4TPMS shows lower melting point $\left(115^{\circ} \mathrm{C}\right)$ as compared to $4 \mathrm{MPMS}\left(158^{\circ} \mathrm{C}\right)$. However, laser damage threshold (LDT) value is expected to be of higher order in these derivative molecules. For 4MPMS, LDT value is $6.93 \mathrm{GW} / \mathrm{cm}^{2}$. With this reference, in the present study, DMPMS single crystal is reported, showing the enhanced thermal stability, nonlinear optical efficiency, and laser damage threshold value. The study of laser damage threshold is carried out with a nanosecond pulsed laser of second harmonic wavelength $532 \mathrm{~nm}$ and pulse width $6 \mathrm{~ns}$. In addition, absorbance/emission and dielectric properties of the material are reported.

DMPMS is a novel organic material and reported for the first time. Thus, correlating between structure and property, computation framework is added using two functionals (B3LYP and M06-2X). The dipole moment, polarizability parameters and electronic contribution of static hyperpolarizability tensors (first order and second order) have been reported. The importance of this study is to find the best performed optical limiting material in order to protect optical sensors and eyes from high power laser. The third-order nonlinear optical properties of DMPMS single crystal are studied from Z-scan technique in a pulsed laser (Nd:YAG) domain at $532 \mathrm{~nm}$. In nanosecond regime, thermal nonlinear effect is prominent and has a potential application toward broadband absorption [26]. To avoid cumulative thermal effect, experiment is performed in low repetition rate of $10 \mathrm{~Hz}$ and data are collected in single-shot operation [27, 28]. Furthermore, optical limiting study is performed by collecting output power by varying input power. The study of nonlinear optical refraction and third-order nonlinear optical susceptibility parameter in the present investigation would facilitate to develop the optoelectronic/nonlinear optical devices.

\section{Material synthesis and crystal growth process}

A chalcone is naturally occurring flavonoid, which is made up of $-\alpha \beta$ unsaturated carbonyl group connected with two aromatic rings. The method in preparation of organic material will play a major role. In the present study, a simple and effective Claisen Schmidt condensation reaction technique was used. The preparation of tosyloxy chalcone derivative involves two steps: (1) preparation of aldehyde group (4-formyl-phenyl)4-methylbenzene-1-sulfonate and (2) chalcone derivative (aldehyde + ketone group). For the synthesis of aldehyde group, 4-tolenesulfonyl chloride (1 mol) (Molychem-98\%) and 4 hydroxy benzaldehyde $(1 \mathrm{~mol})$ (Molychem-98\%) are dissolved in a solvent (tetrahydrofuran (THF)-Sigma aldrich $\geq 99.9 \%$ ) individually and mixed thoroughly. Further, potassium carbonate $\left(\mathrm{K}_{2} \mathrm{CO}_{3}\right)$ is added (1/3rd of 4-hydroxy aldehyde) to the solution and stirred continuously for $5 \mathrm{~h}$ at $70{ }^{\circ} \mathrm{C}$. The glass condenser mechanism is adopted for efficient cooling to avoid solvent (THF) evaporation. After the reaction time, the temperature reduces to room temperature. The final product is poured into icecold water and $2 \mathrm{~N} \mathrm{HCl}$ (small amount) is added to maintain $\mathrm{pH}$ in the solution. The product will settle down in $2 \mathrm{~h}$ and the precipitate can be collected through vacuum filtration and further dried at room temperature for 24-36 h. The product obtained is crystallized from ethanol solvent to increase the purity of the initial compound ( $\geq 96 \%)$.

In step 2 for the preparation of tosyloxy chalcone, the compounds 4-formyl-phenyl-4-methylbenzene-1-sulfonate $(0.1 \mathrm{M})(\geq 96 \%)$ and 3,4-dimethoxyacetophenone (Sigma Aldrich) ( $\geq 98 \%$ ) were taken in 1:1 ratio and dissolved in ethanol solvent with the addition of $\mathrm{NaOH}(15 \%)$. The solution was stirred vigorously for $5 \mathrm{~h}$ at ambient temperature and reaction is monitored through thin-layer chromatography. After completion of reaction, and the precipitate was poured into ice water. When the precipitate settled down at the bottom of the beaker, the product is collected by filtration and is dried at ambient temperature for $24 \mathrm{~h}$. The purity is enhanced by repeated recrystallization process using acetone solvent. The synthesis scheme of DMPMS is shown in Fig. 1. 
<smiles>Cc1ccc(S(=O)(=O)Oc2ccc(C=O)cc2)cc1</smiles>

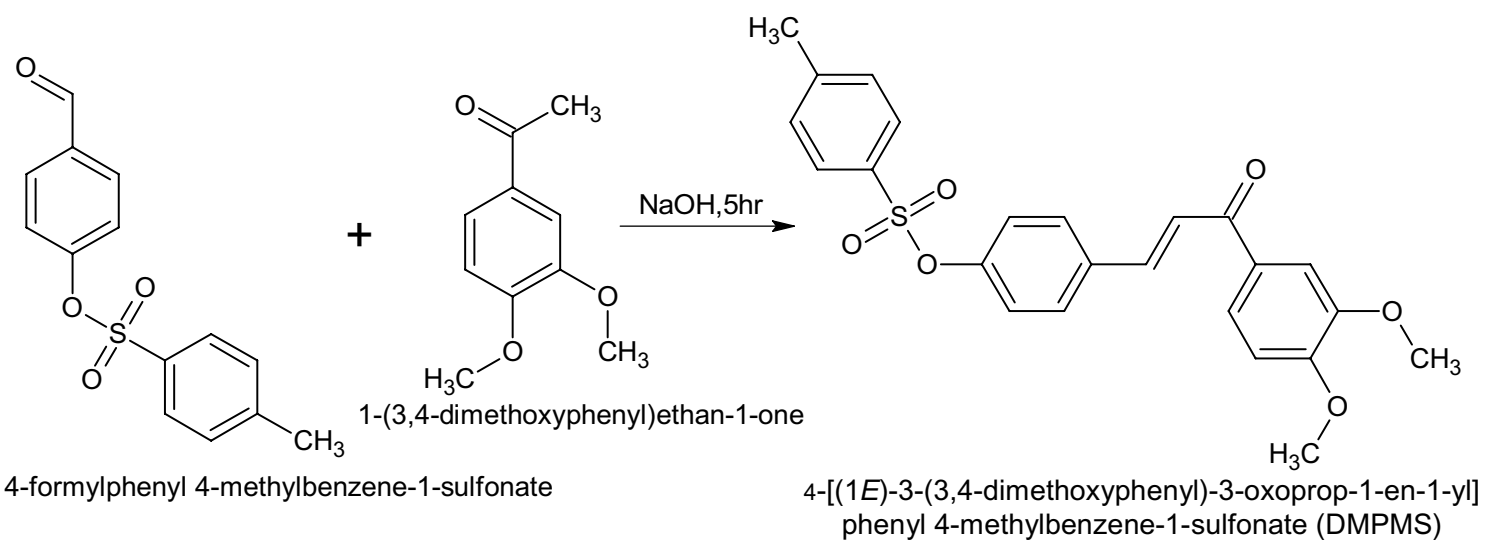

Fig. 1 Synthesis scheme of DMPMS

Several attempts have been made to grow single crystals using acetone solvent but obtained crystals were in the needle shape. Hence, ethanol and acetone combinations were used. During this process, a saturated solution was prepared from ethanol and acetone solvents. By filtration, tiny impurities were removed and the solution was covered with filter paper under a clean atmosphere. After 3 weeks, high-quality single crystals were obtained from the saturated solution (Fig. 2).

\section{Results and discussions}

\subsection{Spectroscopic techniques (FT-IR, FT-Raman and ${ }^{1} \mathrm{H}-\mathrm{NMR}$ )}

The IR transmittance and Raman intensity with respect to peak position were identified and assigned the functional groups with corresponding vibrational frequencies. The data were collected in the range $400-4000 \mathrm{~cm}^{-1}$ in both IR and Raman. The spectrometer of Bruker Alpha KBr FT-IR and BRUKER RFS 27 stand-alone FT-Raman (multiRAM with laser source of Nd:YAG $1064 \mathrm{~nm}$ ) have been used for data collection. The sample was prepared under solid-state technique using $\mathrm{KBr}$ pellet (ratio 10:1).

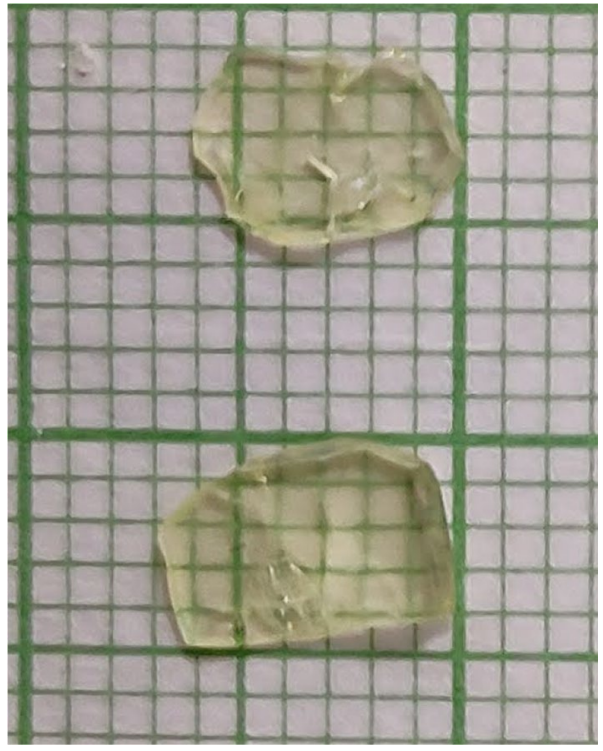

Fig. 2 As grown single crystals of DMPMS

Figure $3 \mathrm{a}$ and $\mathrm{b}$ shows FT-IR and FT-Raman spectrum of DMPMS. The obtained peaks (both in FT-IR and FTRaman spectra) in $3150-3050 \mathrm{~cm}^{-1}$ and $2925-2830 \mathrm{~cm}^{-1}$ correspond to the phenyl ring and methyl $\mathrm{C}-\mathrm{H}$ stretching 

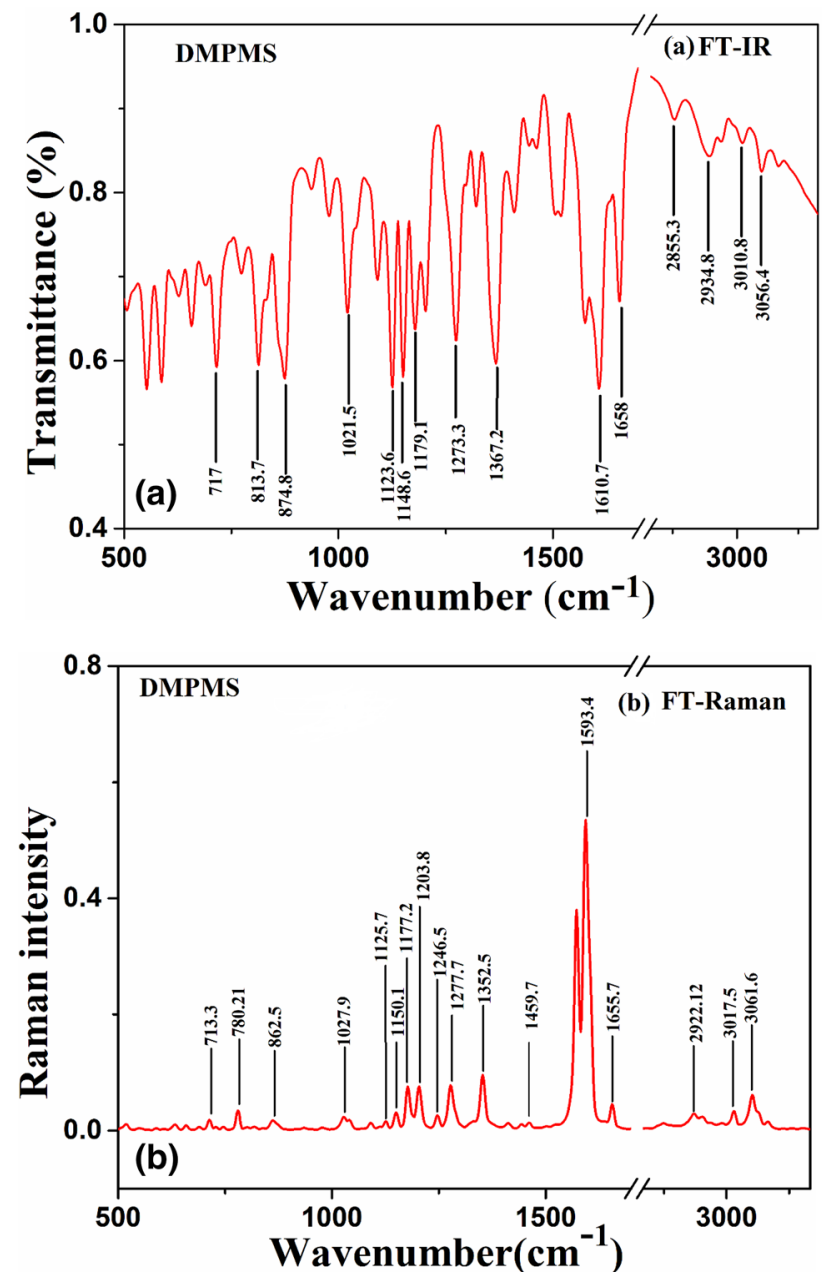

vibration band. The weak multiplicity band as compared to aliphatic $\mathrm{C}-\mathrm{H}$ stretching in these ranges (above/near 3000 $\mathrm{cm}^{-1}$ ) is attributed to the reduction of negative charge in the carbon atom. The peaks $1658 \mathrm{~cm}^{-1}$ and $1655.7 \mathrm{~cm}^{-1}$ correspond to the carbonyl group in FT-IR and FT-Raman spectra. The formation of the chalcone derivative (DMPMS) was confirmed from the peak at $1610.7 \mathrm{~cm}^{-1}$ (IR) and at 1593.4 $\mathrm{cm}^{-1}$ (Raman), which are attributed to enone $(\mathrm{C}=\mathrm{C}-\mathrm{C}=\mathrm{O})$ group. The asymmetric stretching vibrational modes corresponding to $\mathrm{SO}_{2}$ group were assigned to the peaks at 1367.2 $\mathrm{cm}^{-1}, 1148.6 \mathrm{~cm}^{-1}$ (IR) and 1352.5, 1150.1 (Raman), respectively. The peaks at $1123 \mathrm{~cm}^{-1}$ (IR) and $1125 \mathrm{~cm}^{-1}$ (Raman) correspond to the $\mathrm{C}-\mathrm{O}$ stretching vibrations. The other inplane bending vibrations were assigned to the peaks between 1500 and $1000 \mathrm{~cm}^{-1}$, which are attributed to the overlapping of $\mathrm{C}-\mathrm{C}$ band in the aromatic ring. The out-plane bending vibrations were assigned to the peaks below $1000 \mathrm{~cm}^{-1}$.

The number of the hydrogen atoms and molecular type with configuration were identified from ${ }^{1} \mathrm{H}-\mathrm{NMR}$ spectroscopic technique. The data were collected from Agilent WM 400 NMR spectrometer between 1 and 9 ppm under ambient temperature. The solvent $\mathrm{CDCl}_{3}$ is used to make the DMPMS solution and tetramethylsilane is used as an internal standard. The singlet peak at $2.441 \mathrm{ppm}$ (3H atom) and $3.953 \mathrm{ppm}$ (6H atom) corresponds to the methyl group in tosyloxy moiety and di-methoxy group in ketone moiety, respectively. Figure 4 shows doublet peak $(\mathrm{CH}=\mathrm{CH})$ corresponding to the peak positions $7.69-7.65(J=16 \mathrm{~Hz})$ and $7.490-7.451(J=15.6 \mathrm{~Hz})$, respectively. Trans isomerism in the molecule is confirmed from the coupling constant values

Fig. 3 a FT-IR and b FT-Raman spectrum of DMPMS

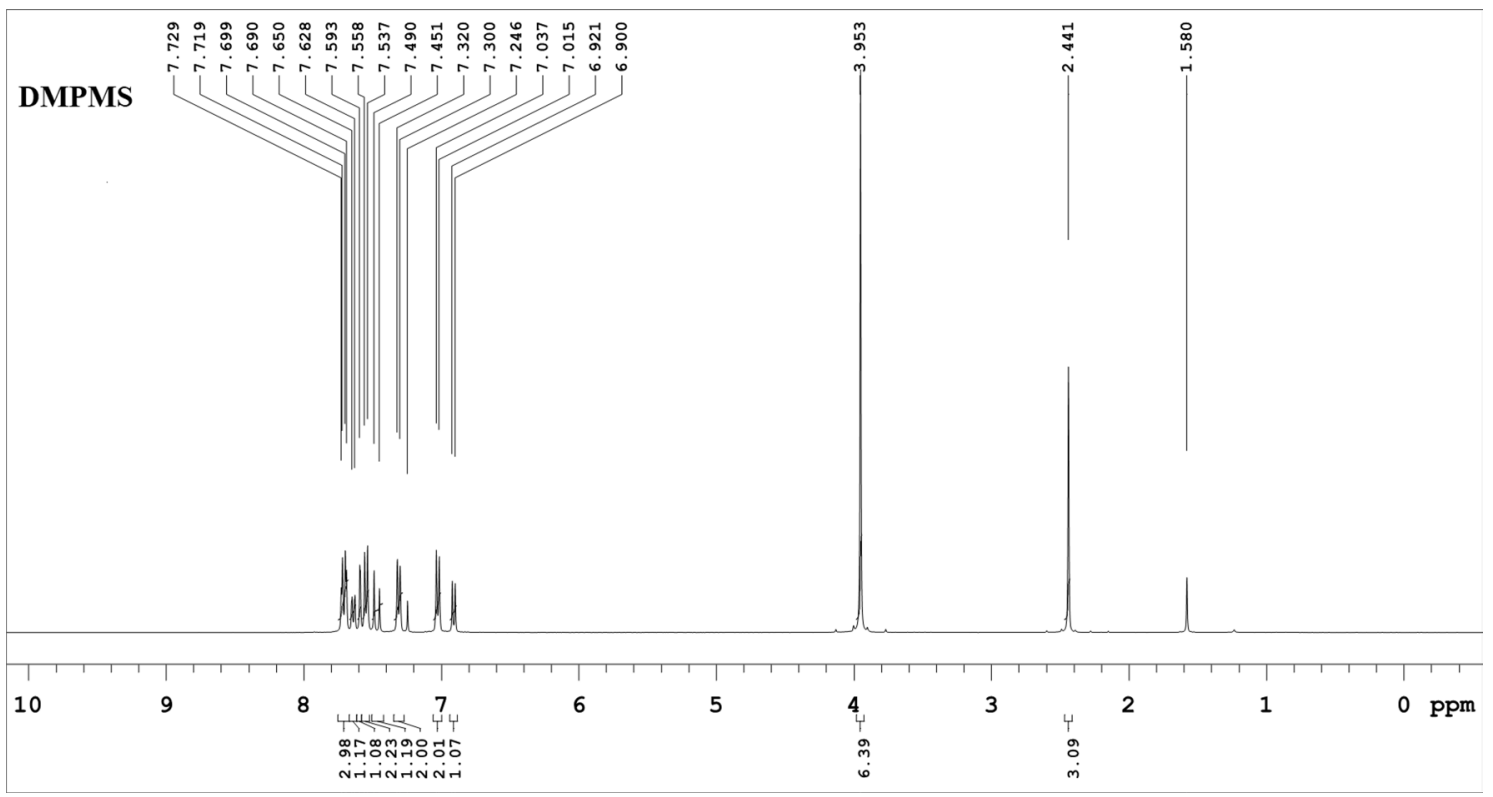

Fig. 4. ${ }^{1} \mathrm{H}-\mathrm{NMR}$ spectrum of DMPMS 
of $\mathrm{CH}=\mathrm{CH}$. All the aromatic rings in the chalcone derivative (DMPMS) are assigned the peaks between 6.9 and 7.8 ppm.

\subsection{Single-crystal X-ray diffraction}

The single-crystal XRD technique was used to get complete information about the molecular and crystal structure and is often more difficult from the other techniques (powder $\mathrm{XRD}$ and spectroscopic techniques). In the single crystal, a flat-faced single crystal was mounted on a goniometer and $\mathrm{X}$-rays are focused on it through the fine-focus sealed tube to collect experimental data. The diffraction data were collected from Rigaku XtaLAB Mini X-ray diffractometer and using If and $\backslash \mathrm{w}$ shutterless scans between the angle $(\theta) 3.15^{\circ}$ and $27.49^{\circ}$ at 293(2) K. Here, a radiation source Mo-K $\mathrm{K}_{\alpha}$ with a wavelength of $0.71075 \AA$ was used. The reduction and processing were performed by SAINT program [29] and the solution of the structure with refinement was performed using SHELXL [30, 31] software.

The displacement parameters of non-H-atoms were refined anisotropically. The deduction of structure with respect to a parameter was carried out using full-matrix least-square on $F^{2}$. The ratio of $\mathrm{H}$-atom and parent-atom (carbon) displacements was refined by setting geometrical positions $(\mathrm{C}-\mathrm{H}=0.93-0.96 \AA)$ with reference to the equivalent isotropic $U$ value (1.2 or 1.5 times). 11,528 reflections were collected which were separated as independent (4827) and unique $(3390-I>2 \sigma(I))$ reflections. From lattice parameters, it is observed that structure belongs to $P 2_{1} / c$ space group in the monoclinic crystal system. The unit cell parameters are $a=13.248(18) \AA, b=7.447(10)$ $\AA, c=21.958(3) \AA, \alpha=90^{\circ}, \beta=101.72(7)^{\circ}$ and $\gamma=90^{\circ}$, respectively. The MERCURY software [32] has been used for generating a molecular structure with a packing diagram also, used for analyzing the intermolecular interactions. Figure 5 shows ORTEP diagram with thermal ellipsoid 50\% probability. The details of the analysis of the structure with the crystallographic data are elucidated in Table 1.

In DMPMS chalcone derivative, the enone group involved by $\mathrm{C} 13=\mathrm{C} 21$ with bond length of $1.310(3) \AA$ belongs to E-configuration. The obtained torsion angle is $-174.2(2)^{\circ}$ with respect to the plane of C9-C19-C21-C13 and corresponding angle to the enone group is $5.2(3)^{\circ}$. The dihedral

Table 1 Crystallograpic data and experimental details of DMPMS

\begin{tabular}{ll}
\hline CCDC number & 1921611 \\
\hline Crystal size $\left(\mathrm{mm}^{3}\right)$ & $0.32 \times 0.32 \times 0.28$ \\
Crystal color & Pale yellow \\
Radiation source & Fine-focus sealed tube \\
Method & If and $\mid$ w shutterless scans \\
Radiation type (wavelength) & Mo- $\mathrm{K}_{\alpha}(0.71075 \AA)$ \\
Molecular formula & $\mathrm{C}_{24} \mathrm{H}_{22} \mathrm{O}_{6} \mathrm{~S}$ \\
Formula weight & 438.48 \\
Temperature $(\mathrm{K})$ & $293(2)$ \\
Unit cell dimensions $(\AA)$ & $a=13.248(18)$, \\
& $b=7.447(10)$ and \\
Cell angles $\left({ }^{\circ}\right)$ & $c=21.958(3)$ \\
Structure and space group & $\alpha=90, \beta=101.72(7), \gamma=90$ \\
Volume $\left(\AA^{3}\right)$ & Monoclinic with $P 2_{1} / c$ \\
$h, k, l$ values & $2121.3(5)$ \\
Parameters & $15,-17 ; 9,-9 ; 28,-22$ \\
$Z$ & 256 \\
Goodness of fit & 4 \\
Reflections measured & 1.040 \\
Observed reflections $(I>2 \sigma(I))$ & 4827 \\
Density $\left(\mathrm{g} / \mathrm{cm}^{3}\right)$ & 3390 \\
$\nabla \rho$ (min), $\nabla \rho($ max $)$ & 1.373 \\
Absorption co-efficient $(\mu)$ & $-0.339 / \mathrm{e} \AA^{-3}, 0.186 / \mathrm{e} \AA^{-3}$ \\
w $R_{2 \text {-all }}$, w $R_{2 \text {-obs }}$ & $0.192 \mathrm{~mm}^{-1}$ \\
$R_{\text {all }}, R_{\text {obs }}$ & $0.1356,0.1213$ \\
\hline
\end{tabular}

Fig. 5 ORTEP molecule diagram with $50 \%$ probability of DMPMS

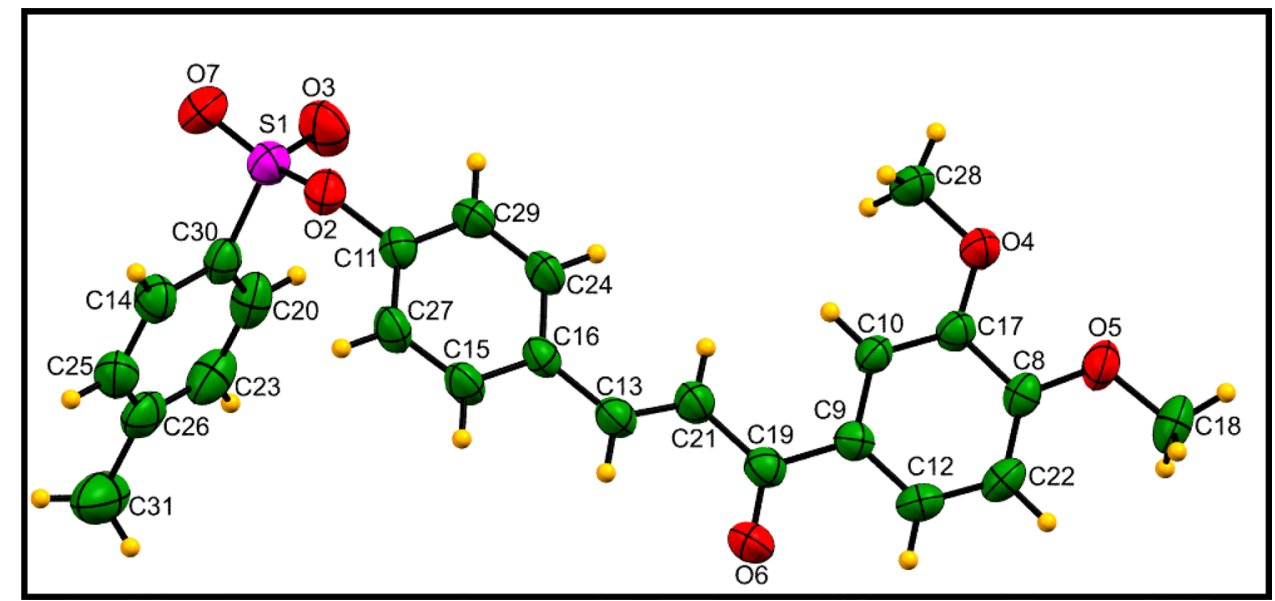


angle between the aromatic rings, the mean plane dihedral angle from enone-dimethoxy phenyl group and tosyloxy group were found to be $41.74^{\circ}, 45.64^{\circ}$, and $1.87^{\circ}$, respectively. The molecule is a twisted structure with a non-planar conformation. The twisting of the structure is due to the presence of the tosyloxy group. In that, sulfonyl group shows distorted tetrahedral geometry, which is close to $120^{\circ}$ $\left(\mathrm{O} 3-\mathrm{S} 1-\mathrm{O} 7=119.9(1)^{\circ}, \mathrm{S} 1-\mathrm{O} 2-\mathrm{C} 11=120.6(1)^{\circ}\right)$, while the angles vary from $102^{\circ}$ to $109^{\circ}[\mathrm{O} 2-\mathrm{S} 1-\mathrm{O} 3=109.9(1)$, $\mathrm{O} 2-\mathrm{S} 1-07=102.8(1), \quad \mathrm{O} 2-\mathrm{S} 1-\mathrm{C} 30=103.85(9)$, $\mathrm{O} 3-\mathrm{S} 1-\mathrm{C} 30=109.4(1)$ and O7-S1-C30 = 109.6(1)]. Hence, the angle of deviation occurs in the tosyloxy group and the molecule takes nonplanar conformation with twisted structure.

The selection of an element in the particular position of the molecule influences the molecular stability. Moreover, the reasonable molecular density and stability of the crystal packing are due to intermolecular interaction and contribution of $\mathrm{C}-\mathrm{H} \cdots \pi$ interaction [33]. The charge transfer takes place between the molecules through hydrogen bonding, which favors the noninversion center packing but the effective charge transfer in the molecule gives centrosymmetric packing with large dipole moment [34]. The planar molecules have conjugated electron orbitals and molecular column stacked in parallel. The intermolecular interaction is effective in perpendicular direction than in a parallel direction.

In the present study, the molecule is stabilized by both $\mathrm{C}-\mathrm{H} \cdots \mathrm{O}$ and $\mathrm{C}-\mathrm{H} \cdots \pi$ intermolecular interactions. The $\mathrm{C}-\mathrm{H} \cdots \mathrm{O} / \mathrm{C}-\mathrm{H} \cdots \pi$ interactions play a crucial role because those intermolecular interactions are ancillary interactions and form stable dimolecular aggregate. The optimization process and alignment of the crystal packing are the initial

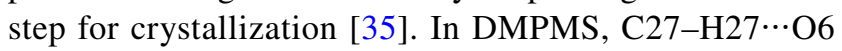

explains the process of obtaining seed crystals from the compound. Similarly, C18-H18A $\cdots \pi$ interactions (stronger interaction than the former) take place from centroid position benzene ring with respect to $\mathrm{C} 16-\mathrm{C} 24$ atoms, which stabilize the molecular crystal packing. Even more, crystal packing is concentrated by $\pi \cdots \pi$ stacking interactions. The stacking contact with various weak $\mathrm{C}-\mathrm{H} \cdots \mathrm{O}(\mathrm{C} 22-\mathrm{H} 22 \cdots \mathrm{O} 7$ and $\mathrm{C} 15-\mathrm{H} 15 \cdots \mathrm{O} 4)$ interactions between the molecules helps in forming an infinite linear chain. The hydrogen contribution corresponding to the intermolecular interaction is shown in Fig. 6. The $\mathrm{C}-\mathrm{H} \cdots \pi$ intermolecular interaction is shown in Fig. 7. The hydrogen bond interactions with corresponding symmetry codes are shown in Table 2 . The selected bond length, bond angle and torsion angle of DMPMS are shown in Table 3. The detailed information about the crystal structure is made available from the CCDC number: 1921611.

\subsection{Powder XRD}

The single-phase formation of the bulk powder crystalline sample was confirmed from the powder XRD technique. The radiation source of $\mathrm{Cu}-\mathrm{K} \alpha$ was used with a wavelength of $1.540562 \AA$ and the spectrum is recorded using Rigaku Ultima IV, between 5 and $40^{\circ}$ (scan rate $1 \%$ min). The crystal structure was determined using EXPO2014 software [36]. The inbuilt Program N-TREOR09 and DICVOL06 have been used for indexing and calculation of reflectionintegrated intensities. Figure 8 a shows experimentally determined powder XRD pattern and Fig. $8 \mathrm{~b}$ show the simulated pattern obtained from the single-crystal XRD data using mercury software. The intensity peaks obtained in powder XRD (experimental) was in accordance with the simulated powder XRD pattern. The unit cell parameters for DMPMS

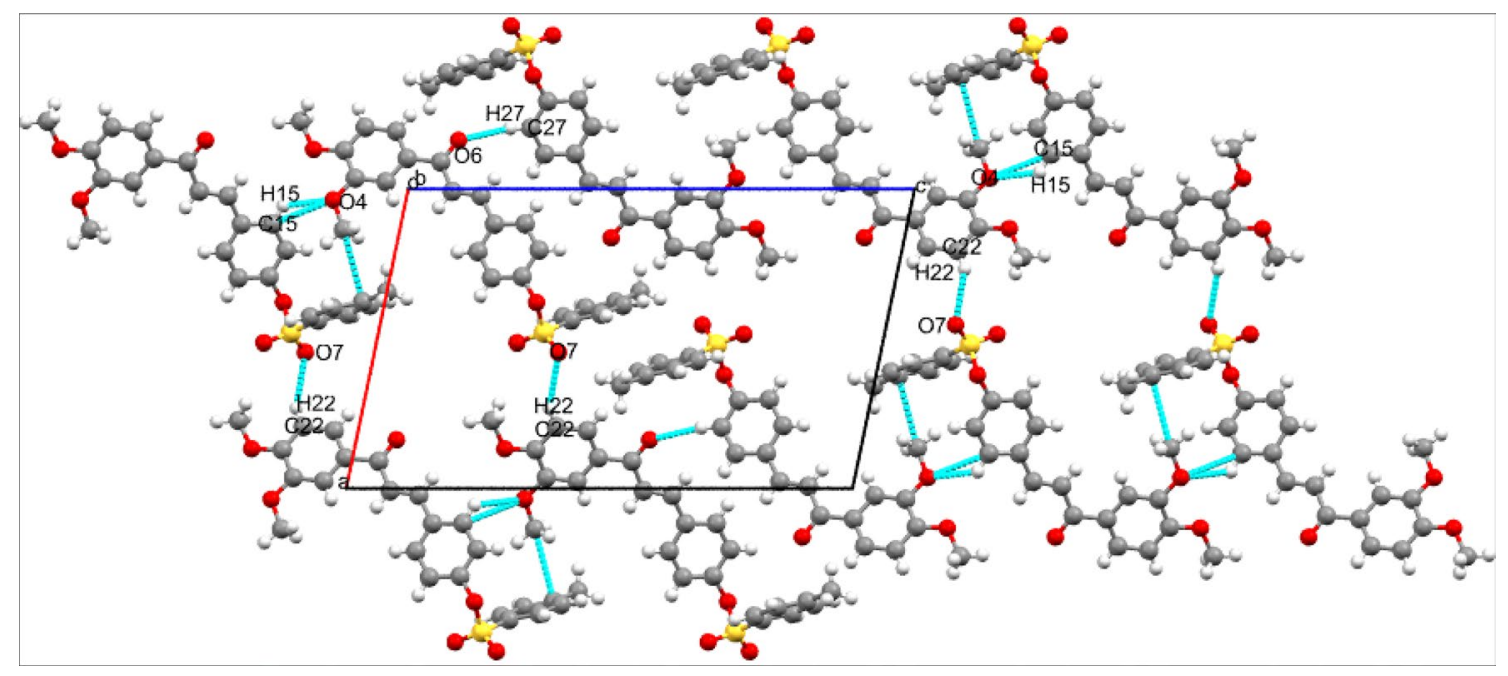

Fig. 6 Hydrogen interaction of the molecule DMPMS along $b$-axis 
Fig. $7 \mathrm{C}-\mathrm{H} \cdots \pi$ intermolecular interactions of DMPMS

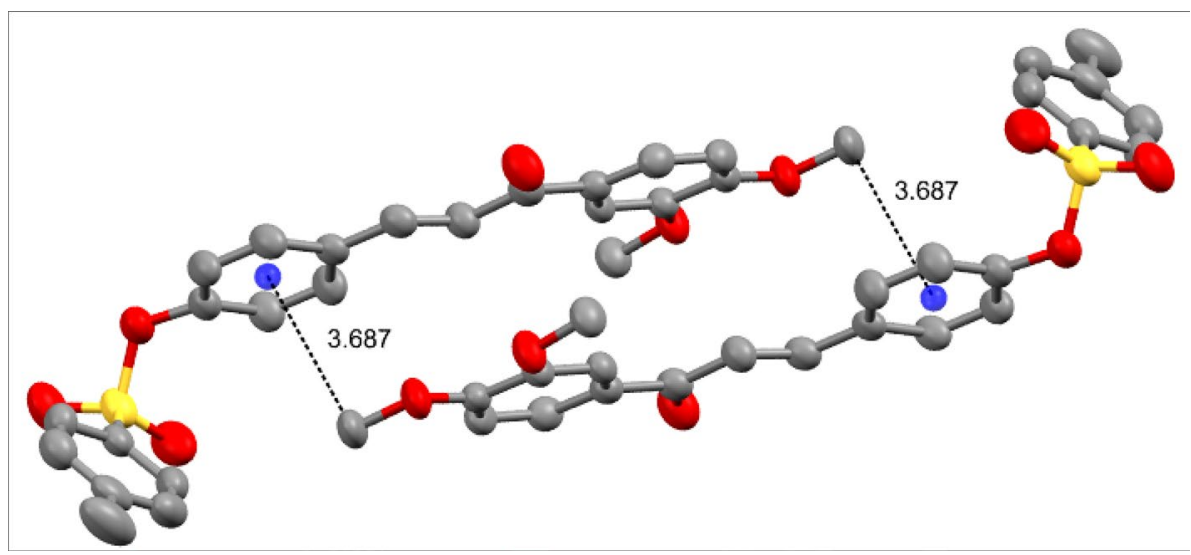

Table 2 Intermolecular interaction of DMPMS

\begin{tabular}{lllll}
\hline $\mathrm{D}-\mathrm{H} \cdots \mathrm{A}$ & $\mathrm{D}-\mathrm{H}(\AA)$ & $\mathrm{H} \cdots \mathrm{A}(\AA)$ & $\mathrm{D} \cdots \mathrm{A}(\AA)$ & $\mathrm{C}-\mathrm{H} \cdots \mathrm{A}$ \\
\hline $\mathrm{C} 22-\mathrm{H} 22 \cdots \mathrm{O} 7$ & 0.93 & 2.715 & 3.568 & $152.80^{\circ}$ \\
$\mathrm{C} 27-\mathrm{H} 27 \cdots \mathrm{O} 6$ & 0.93 & 2.477 & 3.390 & $167.13^{\circ}$ \\
$\mathrm{C} 15-\mathrm{H} 15 \cdots \mathrm{O} 4$ & 0.93 & 2.536 & 3.159 & $124.67^{\circ}$ \\
$\mathrm{C} 18-\mathrm{H} 18 \mathrm{~A} \cdots \pi$ & 0.96 & 2.791 & 3.687 & $155.80^{\circ}$ \\
\hline
\end{tabular}

Symmetry $-1+x, \quad 1 / 2-y,-1 / 2+z, \quad 2-x,-1 / 2+y, \quad 1 / 2-z, \quad x$, $1 / 2-y,-1 / 2+z$

are $a=13.238 \AA, b=7.458 \AA$ and $c=21.899 \AA$; $\alpha=90^{\circ}$, $\beta=101.711^{\circ}, \gamma=90^{\circ}$ and $V=2117.2 \AA^{3}$. The results of lattice parameters (powder XRD (experimental)) are in good agreement with single-crystal XRD (simulated) values (Table 1) and structure belongs to monoclinic with $P 2_{1} / c$ space group.

\subsection{Linear optical properties}

\subsubsection{UV-Vis NIR spectroscopic study}

The absorbance/transmittance is one of the criteria for the selection of third-order nonlinear optical material. The experiment is performed from the near-infrared region to UV-region using SHIMADZU UV160PC UV-VIS-NIR spectrometer in DMF solvent between 280 and $1100 \mathrm{~nm}$. The aromatic ring attached with $\mathrm{C}=\mathrm{O}$ group exhibits a hump behavior at $308 \mathrm{~nm}$ corresponding to the $n-\pi^{*}$ transitions [37]. From Fig. 9 (inset graph), it is observed that cut-off wavelength for DMPMS is $384 \mathrm{~nm}$ due to charge transfer absorbance; this leads to maximum delocalized states in the excited state than in the ground states. The absorption coefficient $\left(\alpha=\frac{2.303 A}{d}\right)$ is calculated from the results of absorbance (A) and thickness $(d)$. Further, the parameter $(\alpha)$ is also used for energy bandgap calculation. The absorption coefficient regarding direct/indirect bandgap transitions is represented by Tauc's plot relation [38]: $\alpha h v=A\left(h v-E_{\mathrm{g}}\right)^{r}$ where $E_{g}$ is the energy bandgap of the material, $A$ is the band edge constant and $r$ represents the optical transition type. The theoretical value of $r$ corresponding to the direct and indirect bandgap is equal to $1 / 2$ and 2 , respectively. The obtained value for direct bandgap is $3.37 \mathrm{eV}$ (Fig. 9). Similarly, theoretical energy bandgap of the material is calculated using the relation $E_{\mathrm{g}}=h c / \lambda_{\mathrm{c}}$. The value of $E_{\mathrm{g}}$ is $3.23 \mathrm{eV}$. This value is very close to the value of direct bandgap. The material with large bandgap leads to high surface damage threshold, which is useful for nonlinear optical device applications.

\subsubsection{Photoluminescence study}

The presence of defects in the crystal provides bound excited states, which creates defects' level. Those defect states were observed from non-destructive mechanism using photoluminescence spectroscopy. The spectra have been collected with an accuracy of $0.5 \mathrm{~nm}$ using Fluoro Max-4CP spectrometer (Ozone-free xenon arc lamp, CW, $150 \mathrm{~W}$ ) with an excitation wavelength of $360 \mathrm{~nm}$. The emission was collected from the detector R928P photon counting PMT (185-850 nm). The emission spectra were collected in the range of $380-700 \mathrm{~nm}$ (Fig. 10). The emission peaks in the blue region $(466 \mathrm{~nm}$, $479 \mathrm{~nm}$ and $490 \mathrm{~nm}$ ) correspond to defect states, attributed from the presence of donor electrons in the aromatic ring. The primary defect state $(466 \mathrm{~nm})$ originated in the blue region from the other involved transitions below the conduction band. However, these defect states obtained in the blue region are due to stacking faults, during the growth process; the two molecules are in opposite faces and one of those plane columns is wrongly arranged as stacking fault [39]. This fault in the crystal packing created point defects due to which the defect state has appeared in the blue region. The defect state at $567 \mathrm{~nm}$ (green emission) is due to the stereogenic carbon atom, which generates the defect states in the crystal lattice [40]. These stereogenic distortions of carbon atom are due to anisotropic shape and are in accordance with dominated intermolecular forces. Moreover, green emission 
Table 3 Selected bond angle, torsion angle and bond length of DMPMS

\begin{tabular}{|c|c|c|c|c|c|c|c|}
\hline Atom number & Bond angle $\left({ }^{\circ}\right)$ & Atom number & Torsion angle $\left({ }^{\circ}\right)$ & Atom number & Torsion angle $\left({ }^{\circ}\right)$ & Atom number & Bond length $(\AA)$ \\
\hline $\mathrm{O} 2-\mathrm{S} 1-\mathrm{O} 3$ & 109.9(1) & $\mathrm{O} 3-\mathrm{S} 1-\mathrm{O} 2-\mathrm{C} 11$ & $52.1(2)$ & C9-C10-C17-O4 & $179.7(2)$ & $\mathrm{S} 1-\mathrm{O} 2$ & $1.592(2)$ \\
\hline $\mathrm{O} 2-\mathrm{S} 1-\mathrm{O} 7$ & $102.8(1)$ & $\mathrm{O} 7-\mathrm{S} 1-\mathrm{O} 2-\mathrm{C} 11$ & $179.1(2)$ & $\begin{array}{l}\mathrm{O} 2-\mathrm{C} 11-\mathrm{C} 27- \\
\mathrm{C} 15\end{array}$ & $-175.2(2)$ & $\mathrm{S} 1-\mathrm{O} 3$ & $1.418(2)$ \\
\hline $\mathrm{O} 2-\mathrm{S} 1-\mathrm{C} 30$ & $103.85(9)$ & $\mathrm{C} 30-\mathrm{S} 1-\mathrm{O} 2-\mathrm{C} 11$ & $64.9(2)$ & $\begin{array}{l}\mathrm{O} 2-\mathrm{C} 11-\mathrm{C} 27- \\
\mathrm{H} 27\end{array}$ & 4.8 & $\mathrm{~S} 1-\mathrm{O} 7$ & $1.417(2)$ \\
\hline $\mathrm{O} 3-\mathrm{S} 1-\mathrm{O} 7$ & $119.9(1)$ & $\mathrm{O} 2-\mathrm{S} 1-\mathrm{C} 30-\mathrm{C} 14$ & $73.4(2)$ & $\begin{array}{l}\text { C29-C11-C27- } \\
\text { C15 }\end{array}$ & $-0.8(3)$ & $\mathrm{S} 1-\mathrm{C} 30$ & $1.750(2)$ \\
\hline $\mathrm{O} 3-\mathrm{S} 1-\mathrm{C} 30$ & $109.4(1)$ & $\mathrm{O} 2-\mathrm{S} 1-\mathrm{C} 30-\mathrm{C} 20$ & $-169.3(2)$ & $\begin{array}{l}\mathrm{O} 2-\mathrm{C} 11-\mathrm{C} 29- \\
\mathrm{C} 24\end{array}$ & $175.4(2)$ & $\mathrm{O} 2-\mathrm{C} 11$ & $1.418(2)$ \\
\hline O7-S1-C30 & 109.6(1) & $\mathrm{O} 3-\mathrm{S} 1-\mathrm{C} 30-\mathrm{C} 14$ & $9.3(2)$ & $\begin{array}{l}\text { C21-C13-C16- } \\
\text { C15 }\end{array}$ & $-176.5(2)$ & $\mathrm{O} 5-\mathrm{C} 8$ & $1.355(3)$ \\
\hline $\mathrm{S} 1-\mathrm{O} 2-\mathrm{C} 11$ & $120.6(1)$ & $\mathrm{O} 3-\mathrm{S} 1-\mathrm{C} 30-\mathrm{C} 20$ & $-35.9(2)$ & $\begin{array}{l}\text { C16-C13-C21- } \\
\text { C19 }\end{array}$ & $179.5(2)$ & O6-C19 & $1.230(3)$ \\
\hline $\mathrm{C} 17-\mathrm{O} 4-\mathrm{C} 28$ & 117.1(2) & $\mathrm{O} 7-\mathrm{S} 1-\mathrm{C} 30-\mathrm{C} 20$ & $-114.4(2)$ & $\begin{array}{l}\mathrm{C} 25-\mathrm{C} 14-\mathrm{C} 30- \\
\mathrm{S} 1\end{array}$ & $177.9(2)$ & $\mathrm{C} 8-\mathrm{C} 17$ & $1.408(3)$ \\
\hline C8-O5-C18 & 118.1(2) & $\mathrm{S} 1-\mathrm{O} 2-\mathrm{C} 11-\mathrm{C} 27$ & 71.1(2) & $\begin{array}{l}\text { C27-C15-C16- } \\
\text { C13 }\end{array}$ & $-178.8(2)$ & C9-C19 & $1.486(3)$ \\
\hline C12-C9-C19 & 119.7(2) & $\mathrm{S} 1-\mathrm{O} 2-\mathrm{C} 11-\mathrm{C} 29$ & $172.0(2)$ & $\begin{array}{l}\mathrm{C} 15-\mathrm{C} 16-\mathrm{C} 24- \\
\mathrm{C} 29\end{array}$ & $-0.4(3)$ & C10-H10 & 0.93 \\
\hline C9-C10-C17 & $121.2(2)$ & $\mathrm{C} 28-\mathrm{O} 4-\mathrm{C} 17-\mathrm{C} 8$ & $-8.1(3)$ & $\begin{array}{l}\text { O6-C19-C21- } \\
\text { C13 }\end{array}$ & $5.2(3)$ & $\mathrm{C} 10-\mathrm{C} 17$ & $1.369(3)$ \\
\hline $\mathrm{O} 2-\mathrm{C} 11-\mathrm{C} 27$ & $117.0(2)$ & $\begin{array}{l}\mathrm{C} 28-\mathrm{O} 4-\mathrm{C} 17- \\
\mathrm{C} 10\end{array}$ & $175.5(2)$ & $\begin{array}{l}\text { C9-C19-C21- } \\
\text { C13 }\end{array}$ & $-174.2(2)$ & $\mathrm{C} 11-\mathrm{C} 29$ & $1.376(3)$ \\
\hline $\mathrm{O} 2-\mathrm{C} 11-\mathrm{C} 29$ & $120.7(2)$ & $\mathrm{C} 18-\mathrm{O} 5-\mathrm{C} 8-\mathrm{C} 17$ & $-5.3(3)$ & $\begin{array}{l}\text { C23-C20-C30- } \\
\text { S1 }\end{array}$ & $-178.3(2)$ & $\mathrm{C} 12-\mathrm{H} 12$ & 0.93 \\
\hline C27-C11-C29 & $122.1(2)$ & $\mathrm{C} 18-\mathrm{O} 5-\mathrm{C} 8-\mathrm{C} 22$ & $-0.5(3)$ & $\begin{array}{l}\mathrm{C} 20-\mathrm{C} 23-\mathrm{C} 26- \\
\mathrm{C} 31\end{array}$ & $0180.0(3)$ & C13-H13 & 0.93 \\
\hline $\mathrm{C} 16-\mathrm{C} 13-\mathrm{C} 21$ & $127.6(2)$ & $\mathrm{O} 5-\mathrm{C} 8-\mathrm{C} 17-\mathrm{O} 4$ & $179.6(2)$ & C10-C9-C19-O6 & $-176.3(2)$ & $\mathrm{C} 13-\mathrm{C} 16$ & $1.461(3)$ \\
\hline O6-C19-C9 & $120.4(2)$ & $\mathrm{O} 5-\mathrm{C} 8-\mathrm{C} 17-\mathrm{C} 10$ & $-179.8(2)$ & $\begin{array}{l}\mathrm{C} 10-\mathrm{C} 9-\mathrm{C} 19- \\
\mathrm{C} 21\end{array}$ & $3.2(3)$ & $\mathrm{C} 13-\mathrm{C} 21$ & $1.310(3)$ \\
\hline C9-C19-C21 & $119.2(2)$ & C22-C8-C17-O4 & $0.3(3)$ & C12-C9-C19-O6 & $3.8(3)$ & C15-H15 & 0.93 \\
\hline C13-C21-C19 & $123.7(2)$ & $\mathrm{O} 5-\mathrm{C} 8-\mathrm{C} 22-\mathrm{C} 12$ & $0.2(3)$ & $\begin{array}{l}\mathrm{C} 12-\mathrm{C} 9-\mathrm{C} 19- \\
\mathrm{C} 21\end{array}$ & $-176.8(2)$ & $\mathrm{C} 15-\mathrm{C} 16$ & $1.389(3)$ \\
\hline C25-C26-C31 & $120.6(3)$ & $\begin{array}{l}\text { C19-C9-C12- } \\
\text { C22 }\end{array}$ & $179.9(2)$ & C9-C10-C17-O4 & $179.7(2)$ & C19-C21 & $1.470(3)$ \\
\hline
\end{tabular}

is less intense as compared to blue emission in the present study and DMPMS is adequately favorable for blue-light LED applications.

\subsection{Thermal studies}

The melting point, decomposition, weight loss, and phase transition in the material are obtained from TGA/DTA (thermogravimetric analysis and differential thermal analysis) technique. The sample quantity of $2.041 \mathrm{mg}$ was taken in a crucible with a temperature range from RT to $600{ }^{\circ} \mathrm{C}$. The data are recorded from NETZSCH STA 2500 under nitrogen atmosphere, at the rate of $10 \% \mathrm{~min}$. The weight loss (TG) vs temperature and microvolt/mg (DT) vs temperature graphs were plotted and are shown in Fig. 11. The process of the irreversible endothermic peak in the vicinity of $139.7^{\circ} \mathrm{C}$ corresponds to the melting point of the sample in DTA spectra. The sharpness in peak shows good crystallinity behavior and there is no additional peak before the melting point, which illustrates the absence of isothermic transition and confirms the purity of the powder crystalline sample. In TGA curve, the material is thermally stable up to $258^{\circ} \mathrm{C}$ and first phase transition takes place between $258^{\circ} \mathrm{C}$ and $383^{\circ} \mathrm{C}$, which confirm the decomposition of the material. The peak in the DTA curve has vicinity of $350^{\circ} \mathrm{C}$ corresponding to the weight loss in the TG curve. There is second phase transition in the TGA curve above $383{ }^{\circ} \mathrm{C}$. The weight loss in the TG curve is due to evaporation or degradation of the sample. 
Fig. 8 a Bulk powder XRD pattern and $\mathbf{b}$ simulated powder XRD pattern of DMPMS

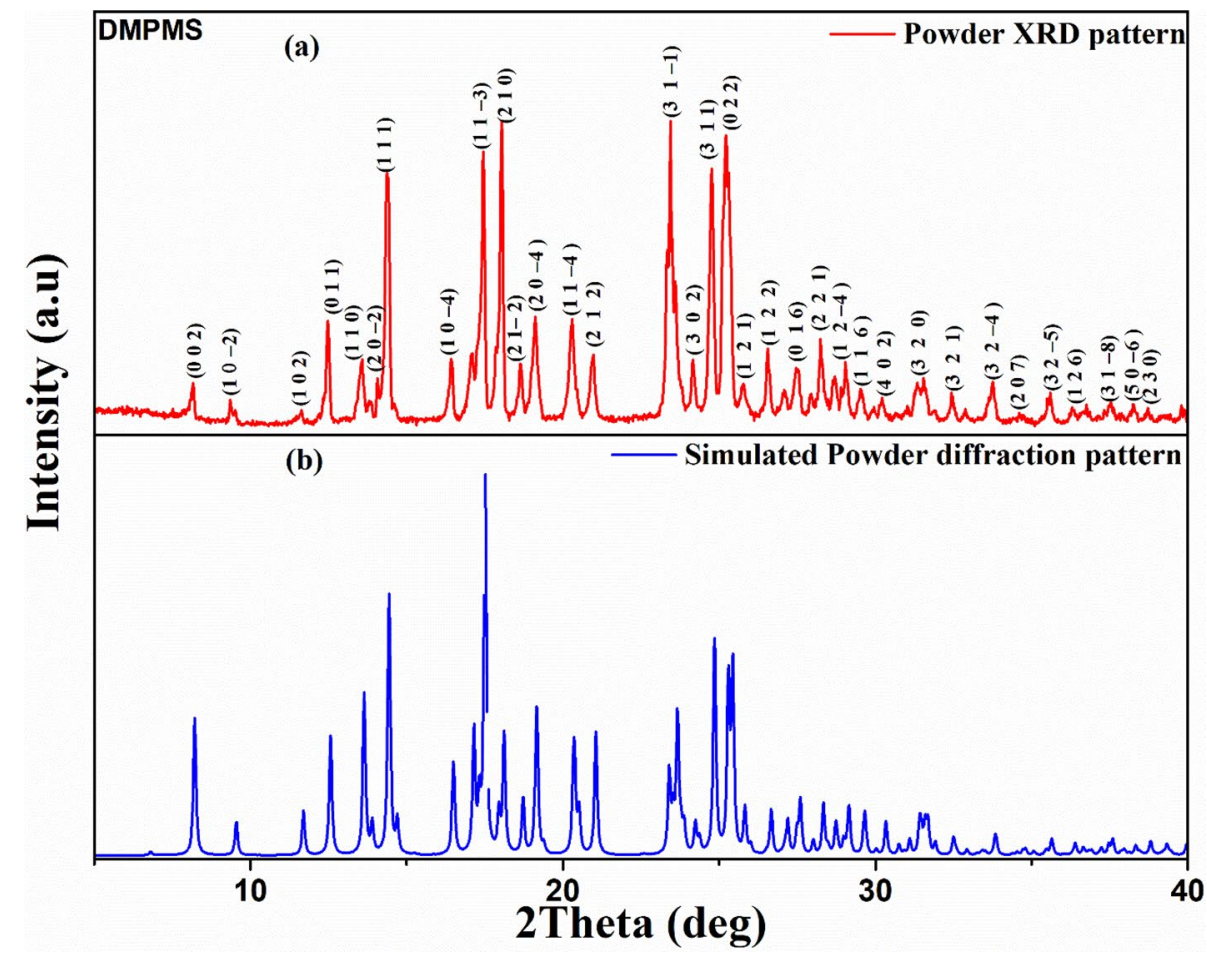

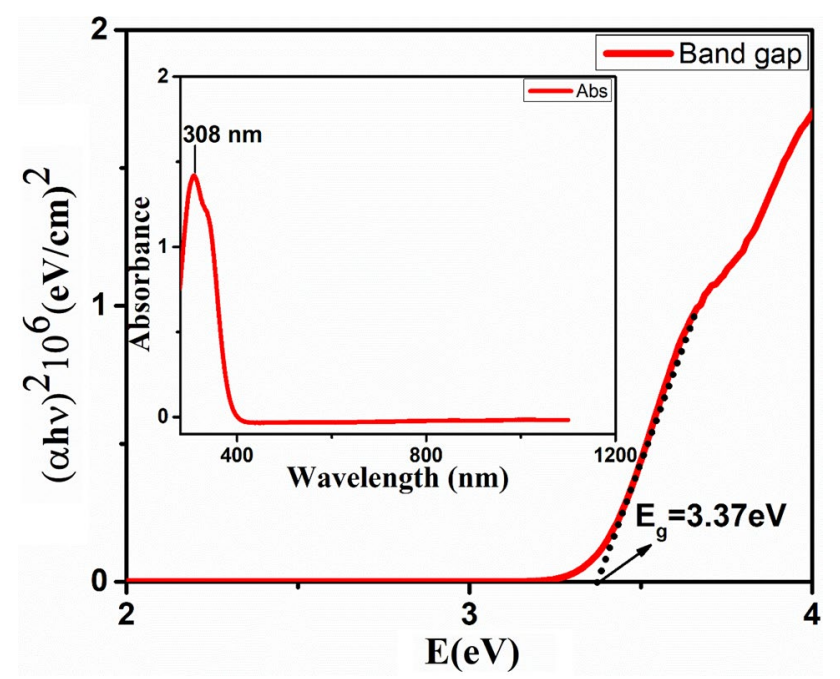

Fig. 9 Optical band gap and inset graph show the absorbance spectra of DMPMS

\subsection{Dielectric studies}

The electronic polarizability parameter governs the nonlinear optical process. It is necessary to correlate electrical and nonlinear optical properties, which is easily accessible [41]. The distribution of the electric field in the material is investigated from the dielectric measurement using HIOKI IM 3536 LCR meter under two-probe method between $1 \mathrm{kHz}$ and $5 \mathrm{MHz}$ at room temperature. The grown crystal acts like

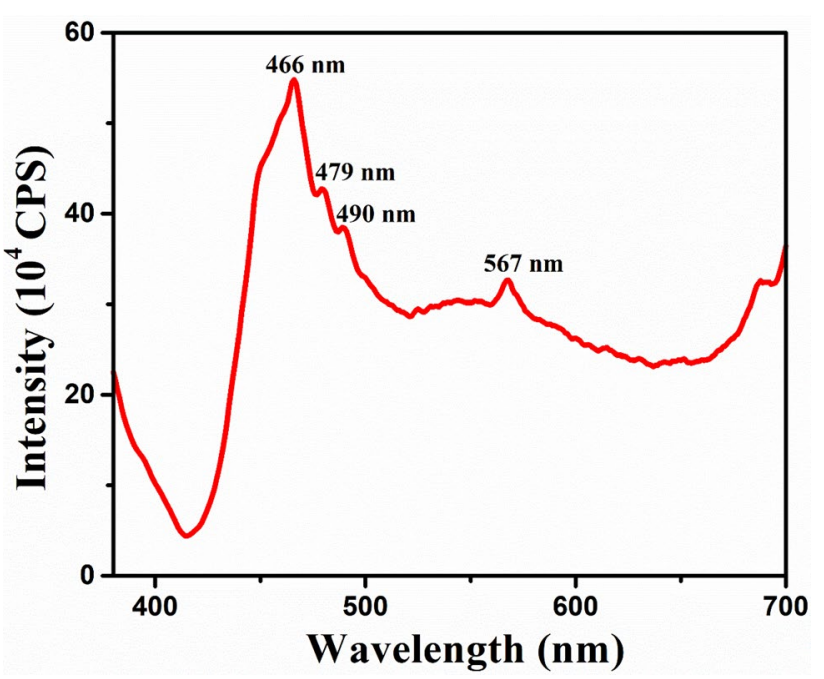

Fig. 10 Photoluminescence spectrum of DMPMS

parallel plate capacitor when the polished parallel surfaces are in ohmic contact with electrodes. Silver paste is used for tight packing of the electrode with the surface. To reduce external polarization from the air molecule, the sample is placed above room temperature $\left(40{ }^{\circ} \mathrm{C}\right)$ for $6 \mathrm{~h}$. Furthermore, the dielectric constant and the dielectric loss factor are taken into the account as dielectric parameters of the grown single crystal. The parameter $\varepsilon_{\mathrm{r}}$ is calculated from the following relation 


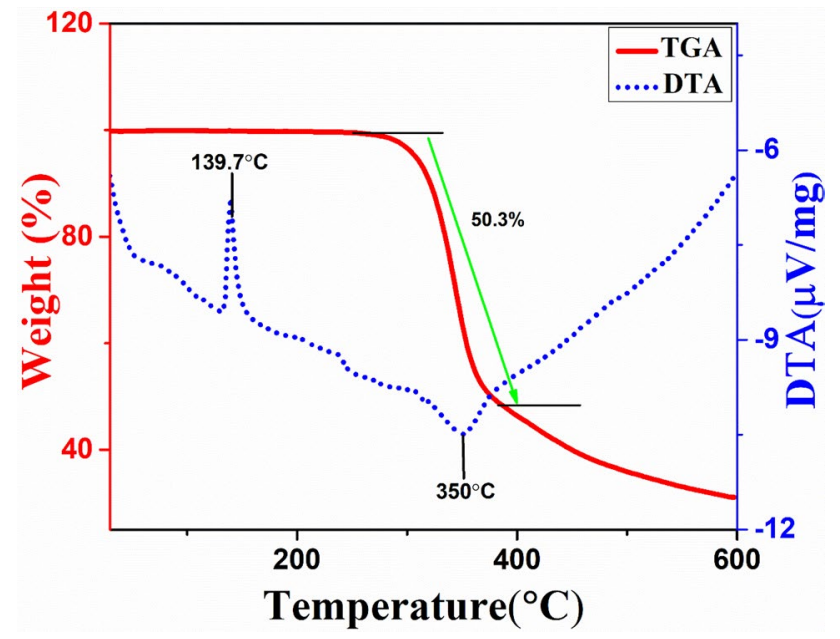

Fig. 11 TGA/DTA curve of DMPMS

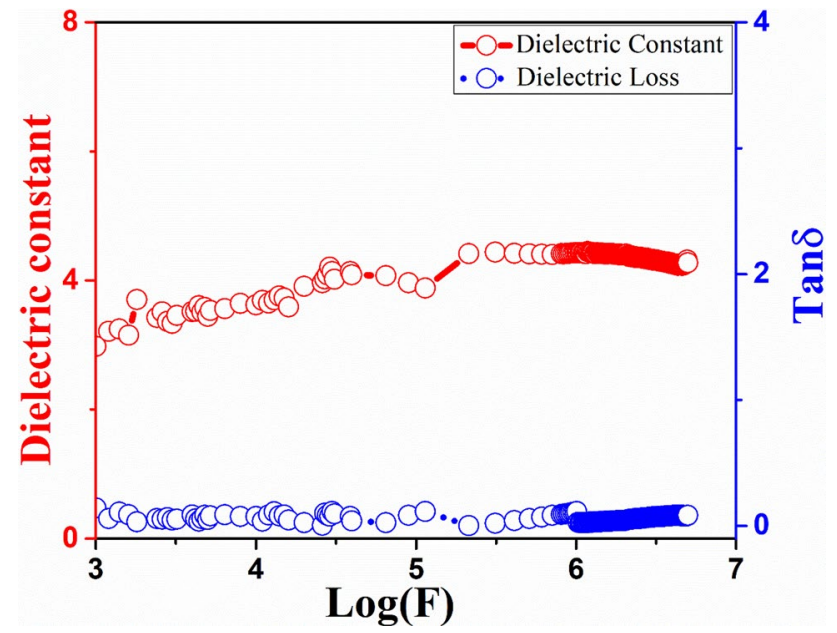

Fig. 12 The dielectric constant and dielectric loss factor of DMPMS

$\varepsilon_{\mathrm{r}}=\frac{C_{\mathrm{p}} d}{\varepsilon_{0} A}$

where $\varepsilon_{0}$ is the permittivity of free space $\left(8.854 \times 10^{-12} \mathrm{~F} / \mathrm{m}\right), C_{\mathrm{p}}$ the capacitance value, $d$ the thickness of the material and $A$ the area of cross-section.

Figure 12 shows the plot of dielectric constant and dielectric loss factor of the material. It is observed that all polarization mechanisms are active at low frequency and major contribution is from space charge carriers. At high-frequency regime, dielectric constant value is found to be 4.42 at $1 \mathrm{MHz}$ due to active electronic polarizability contribution since the other mechanisms cease at this frequency. However, charge distribution has no time to align in parallel hence the contribution is purely electronic. The low dielectric constant materials have reduced phase mismatch that leads to high second-order optical nonlinearity; unfortunately, the grown crystal belongs to the centrosymmetric crystal system. The dielectric loss factor is 0.025 at $1 \mathrm{MHz}$. The smaller value will enhance the optical quality of the single crystal.

\subsection{Electronic polarizability calculations}

Electronic polarizability at high-frequency regime using dielectric constant, the major contribution is electronic. Due to the fact, electronic polarizability parameter is calculated from the phenomenological approach and the band structure model. The high-frequency dielectric constant $\left(\varepsilon_{\infty}\right)$ is interdependent with the parameters of Penn model [42], Fermi energy, valance plasma energy, electronic polarizability, and so on. In any organic crystals, valance electron plasma energy is maximum; hence, band structure of Penn model is appropriate. The valance electron plasma energy $\left(\hbar \omega_{\mathrm{P}}\right)$ depends on molecular weight $(M=438.48 \mathrm{~g} / \mathrm{mol})$, density $(\rho)$, and total number of valance electron $(Z=158)$ and is given as follows

$\hbar \omega_{\mathrm{P}}=28.8 \sqrt{\frac{Z \rho}{M}}$,

where the values of $M=438.48 \mathrm{~g} / \mathrm{mol}$ and $\rho=1.373 \mathrm{~g} / \mathrm{cm}^{3}$, respectively.

In organic crystals/semiconductors with high valance electron plasma energy $\left(\hbar \omega_{\mathrm{P}}\right)$ such that $\varepsilon_{\infty}$ explicitly depends on Penn energy:

$\varepsilon_{\infty}=1+\left(\frac{\hbar \omega_{\mathrm{p}}}{E_{\mathrm{P}}}\right)^{2}\left[1-\left[\frac{E_{\mathrm{P}}}{4 E_{\mathrm{F}}}\right]+\frac{1}{3}\left[\frac{E_{\mathrm{P}}}{4 E_{\mathrm{F}}}\right]^{2}\right]$,

where $E_{\mathrm{P}}$ is Penn gap and $E_{\mathrm{F}}$ Fermi energy. Here, $\left(\hbar \omega_{\mathrm{P}}\right)^{2}$ signifies the strength of the optical transitions while Penn gap represents optical influence in electronic transitions. Presumably, Penn gap depends on the iconicity of chemical bonds [43]. The term given in bracket is assumed to be 1 and named as $S_{0}$ (hereafter). According to Penn model, $S_{0}=$ 1 but the parameter $S_{0}$ depends on $E_{\mathrm{P}}$ and $E_{\mathrm{F}}$ and is given by

$E_{\mathrm{P}}=\frac{\hbar \omega_{\mathrm{p}}}{\sqrt{\left.\varepsilon_{\infty}-1\right)}}$

$E_{\mathrm{F}}=0.2948\left(\hbar \omega_{\mathrm{P}}\right)^{4 / 3}$,

$S_{0}=1-\left[\frac{E_{\mathrm{P}}}{4 E_{\mathrm{F}}}\right]+\frac{1}{3}\left[\frac{E_{\mathrm{P}}}{4 E_{\mathrm{F}}}\right]^{2}$.

The value of $S_{0}$ is 0.82 for DMPMS, and is a dependent factor in electronic polarizability. 
Table 4 Electronic polarization parameters of DMPMS

\begin{tabular}{ll}
\hline Parameters & Values \\
\hline Plasma energy & $20.25 \mathrm{eV}$ \\
Penn energy & $10.94 \mathrm{eV}$ \\
Fermi energy & $16.12 \mathrm{eV}$ \\
Electronic polarizability $\alpha\left(10^{-23} \mathrm{~cm}^{3}\right)$ & \\
Using Penn analysis & 6.11 \\
Using Clausius-Mossotti analysis & 6.74 \\
Using the Lorentz-Lorentz equation & 4.39 \\
\hline
\end{tabular}

The value of $E_{\mathrm{P}}(=10.94)$ is calculated from the above the relation using a high-frequency dielectric constant value $\left(\varepsilon_{\infty}=4.42\right)$.

The electronic polarizability is calculated from the Penn model and is given by [44]

$\alpha=\frac{\left(\hbar \omega_{\mathrm{P}}\right)^{2} S_{0}}{\left(\hbar \omega_{\mathrm{P}}\right)^{2} S_{0}+3 E_{\mathrm{P}}{ }^{2}} \times\left[\frac{M}{\rho}\right] \times 0.396 \times 10^{-24} \mathrm{~cm}^{3}$.

The value of $\alpha$ from Penn model is found to be $6.11 \times 10^{-23} \mathrm{~cm}^{3}$.

The electronic polarizability is expressed from Clausius-Mossotti equation and is given by this relation [45]

$\alpha=\frac{3 M}{4 \pi N_{\mathrm{a}} \rho}\left(\frac{\varepsilon_{\infty}-1}{\varepsilon_{\infty}+2}\right) \mathrm{cm}^{3}$.

The value of $\varepsilon_{\infty}$ is equal to the value of the square of linear refractive index and above equation is expressed from Maxwell relations, which involve Lorentz-Lorentz equation. Further, the $\alpha$ takes into the form as [42, 45]

$\alpha=\frac{3 M}{4 \pi N_{\mathrm{a}} \rho}\left(\frac{n_{0}^{2}-1}{n_{0}^{2}+2}\right) \mathrm{cm}^{3}$

where $n_{0}$ is the linear refractive index $\left(n_{0}=1.61\right)$ and $N_{\mathrm{a}}$ the Avogadro's number.

Table 4 shows all the electronic polarizability parameters obtained by phenomenological approach and the results are in good agreement with the band structure of Penn model.

\subsection{Laser damage threshold study}

Laser damage threshold (LDT) has been determined to understand the stability of the material with respect to laser light. The experimental arrangement uses a Q-switched NdYAG laser (Quanta-Ray INDI, Spectra Physics) with a pulse width $6 \mathrm{~ns}$ and pulse train obtained at $532 \mathrm{~nm}$. The applied energy is monitored from Newport power meter (843-R). The flat-faced crystal with a thickness of $2 \mathrm{~mm}$ is taken for LDT study. The laser beam power is controlled using filters. The beam splitter is used to split into two beams with an equal amount of beam power. Furthermore, one can be used as a reference and another beam is used to irradiate the sample through the lens with a focal length of $4 \mathrm{~cm}$. LDT value is calculated from the given relation, i.e.,

$\operatorname{Power} \operatorname{density}\left(P_{\mathrm{d}}\right)=\frac{E}{\tau \pi r^{2}} \mathrm{GW} / \mathrm{cm}^{2}$

where $\tau$ is the pulse width, $r$ beam spot size and $E$ the input energy

The crystal-damaged surfaces can be found once the light gets scattered from the crystal. The amount of energy used to produce damage on the surface and that same energy is used for the calculation of damage threshold value. The applied energy is $2.6 \mathrm{~mJ}$ and corresponding LDT value of the crystal is found to be $12.01 \mathrm{GW} / \mathrm{cm}^{2}$. The obtained value is much greater than that for other chalcone derivatives: methoxyANC $3.98 \mathrm{GW} / \mathrm{cm}^{2}$ and ethoxy-ANC $5.28 \mathrm{GW} / \mathrm{cm}^{2}$ [15], APTP/APBDP $1.5 \mathrm{GW} / \mathrm{cm}^{2}[46]$ and 4 MPNP $1.2 \mathrm{GW} / \mathrm{cm}^{2}$ [47].

\subsection{Electronic contribution parameters of chalcone derivative DMPMS}

The selection of nonlinear optical material plays the crucial role in practical applications because it must satisfy in both experimental and theoretical approaches. In the present investigations, a theoretical model is applied to know about the structure-property relationship of the NLO crystal. The parameters such as dipole moment, first- and second-order hyperpolarizability tensors and electronic polarizability are analyzed by quick and inexpensive quantum chemistry technique via Density Functional Theory (DFT) using B3LYP/6-311++G (d.p) and M06-2X/6-311++G (d.p) set basis [48-50]. Gaussian09 package [51] has been used to perform all the quantum chemical calculations. Furthermore, the finite field (FF) method is used at the molecular level for determining all the NLO parameters such as hyperpolarizability (first and second order), dipole moment and electronic polarizability using B3LYP and M06-2X functional and the results are compared. By considering the weak system, the static electric field is applied and the energy $(E)$ expression takes the form

$$
\begin{aligned}
E= & E^{0}-\sum_{i} \mu_{i} F^{i}-\frac{1}{2} \sum_{i j} \alpha_{i j} F^{i} F^{j}-\frac{1}{6} \sum_{i j k} \beta_{i j k} F^{i} F^{j} F^{k} \\
& -\frac{1}{24} \sum_{i j k l} \gamma_{i j k l} F^{i} F^{j} F^{k} F^{l}+\cdots,
\end{aligned}
$$

where $E^{0}, F^{i}, \mu_{i}, \alpha_{i j}, \beta_{i j k}$ and $\gamma_{i j k l}$ are the unperturbed energy, field at the origin, dipole moment, polarizability, first-order hyperpolarizability and second-order hyperpolarizability, respectively (Table 5). 
Table 5 Electronic contribution parameters of dipole moment (Debye), polarizability ( $\alpha$ and $\Delta \alpha$ in $10^{-24}$ esu) and hyperpolarizability (first order in $10^{-30}$ esu and second order in $10^{-40}$ esu) using basic set B3LYP/6-311++G(d.p) and M06-2X/6-311++G(d.p) DMPMS \begin{tabular}{lll}
\hline $\begin{array}{l}\text { Electronic param- } \\
\text { eters }\end{array}$ & Using B3LYP functional & $\begin{array}{l}\text { Using M06-2X } \\
\text { functional }\end{array}$
\end{tabular}

\begin{tabular}{lccccr}
\hline$\mu$ & $\beta_{y y y}$ & 4.042 & 1.281 & 3.880 & 0.703 \\
$\mu_{x}$ & $\beta_{x x z}$ & 1.922 & 5.452 & 1.396 & -4.096 \\
$\mu_{y}$ & $\beta_{x y z}$ & 2.146 & 3.229 & 3.522 & 0.976 \\
$\mu_{z}$ & $\beta_{y y z}$ & -2.835 & 0.130 & 0.836 & -0.181 \\
$\alpha_{x x}$ & $\beta_{x z z}$ & 52.02 & 3.140 & 72.36 & -1.401 \\
$\alpha_{y y}$ & $\beta_{y z z}$ & 32.12 & -2.517 & 48.91 & 0.830 \\
$\alpha_{z z}$ & $\beta_{z z z}$ & 96.19 & -22.34 & 31.02 & -0.386 \\
$\alpha_{x y}$ & $\beta_{\text {tot }}$ & 11.50 & 19.22 & 0.797 & 11.85 \\
$\alpha_{x z}$ & $\gamma_{x x x x}$ & 22.05 & 108.8 & 5.916 & 68.47 \\
$\alpha_{y z}$ & $\gamma_{y y y y}$ & 4.615 & -53.53 & -1.610 & -24.26 \\
$\langle\alpha\rangle$ & $\gamma_{z z z z}$ & 60.12 & -55.30 & 50.76 & -44.21 \\
$\Delta \alpha$ & $\gamma_{x x y y}$ & 106.7 & -14.03 & 130.5 & -129.6 \\
$\beta_{x x x}$ & $\gamma_{x x z z}$ & 5.019 & 25.05 & -1.532 & 40.54 \\
$\beta_{x x y}$ & $\gamma_{y y z z}$ & 2.74 & 20.30 & 9.262 & 24.67 \\
$\beta_{x y y}$ & $\gamma_{\text {tot }}$ & 1.131 & -37.97 & 1.459 & -25.77 \\
\hline
\end{tabular}

The scalar factor was calculated by considering tensors or vector components such as dipole moment, mean polarizability and anisotropic polarizability from the following relations,

$\mu_{\mathrm{tot}}=\sqrt{\mu_{x}^{2}+\mu_{y}^{2}+\mu_{z}^{2}}$,

$(\langle\alpha\rangle)$ where $\alpha=\frac{1}{3}\left(\alpha_{x x}+\alpha_{y y}+\alpha_{z z}\right)$, extends from negative charge to positive charge part in the molecule as observed in B3LYP functional. The linear and third-order polarizabilities are usually calculated along the dipole orientation and it can be seen that maximum dipole moment occurs for $z$-component (B3LYP functional) and $y$-component (M06-2X). However, the total dipole moment in B3LYP and M06-2X functional is 4.042 Debye and 3.880 Debye, respectively, which are almost equal. Even more, an inter-dependent parameter such as electronic polarizability is found to be maximum along $z$-direction ( $\alpha_{z z}=96.19 \times 10^{-24}$ esu) for the B3LYP basis set. Similarly, polarizability in M06-2X is found to be maximum along $x$-direction $\left(\alpha_{x x}=72.36 \times 10^{-24} \mathrm{esu}\right)$. The values of anisotropic polarizability and average polarizability are obtained as $106.7 \times 10^{-24}$ esu and $60.12 \times 10^{-24}$ esu (in B3LYP functional) $130.5 \times 10^{-24} \mathrm{esu}$ and $50.76 \times 10^{-24} \mathrm{esu}$ (in M06-2X functional), respectively. The polarizability parameter leads a major role that aligns the polarized molecule in a bulk with an external electric field. As a result, the index of refraction gets modified and allows the switching light to pass through it. According to a recent study $[52,53]$, four-wave degenerate mixing parameter $\chi^{(3)}$ is directly related to the molecular orientation of anisotropic parameter $\Delta \alpha$. The structure modification and design based on structure configuration enhance the polarizability due to strong donor-acceptor motif in the molecular structure. Due to this fact, in the static mode, the molecule is assumed as non-centrosymmetric in the gas phase, and first-order hyperpolarizability parameter does not vanish in DMPMS. According to Kleinman symmetry relation [54], first-order hyperpolarizability tensor has 27 components of the third rank tensor, which is reduced to 10 components. The maximum value of the first-order hyperpolarizabil-

$\Delta \alpha=\frac{1}{\sqrt{2}} \sqrt{\left(\alpha_{x x}-\alpha_{y y}\right)^{2}+\left(\alpha_{y y}-\alpha_{z z}\right)^{2}+\left(\alpha_{z z}-\alpha_{x x}\right)^{2}+6 \alpha_{x y}^{2}+6 \alpha_{y z}^{2}+6 \alpha_{z x}^{2}}$.

The first-order electronic hyperpolarizability $\left(\beta_{\text {ele }}\right)$ is calculated from the relation, ity found along $z$-direction $\left(\beta_{z z z}=-22.348 \times 10^{-30} \mathrm{esu}\right)$ is measured in B3LYP functional. The fact that the value of

$\beta_{\text {ele }}=\sqrt{\left(\beta_{x x x}+\beta_{x y y}+\beta_{x z z}\right)^{2}+\left(\beta_{y y y}+\beta_{y z z}+\beta_{y x x}\right)^{2}+\left(\beta_{z z z}+\beta_{z x x}+\beta_{z y y}\right)^{2}}$.

Similarly, the second-order electronic hyperpolarizability $\left(\gamma_{\text {ele }}\right)$ is obtained from the following relations,

$\gamma_{\mathrm{ele}}=\frac{1}{5}\left[\gamma_{x x x x}+\gamma_{y y y y}+\gamma_{z z z z}+2\left(\gamma_{x x y y}+\gamma_{x x z z}+\gamma_{y y z z}\right)\right]$.

The value of dipole moment for $z$-component is observed maximum ( $\mu_{z}=-2.835$ Debye) in B3LYP but in M06-2X, the dipole moment is maximum along $y$-component ( $\mu_{y}=3.5228$ Debye). The electronic dipole moment vector dipole moment, electronic polarizability and first-order hyperpolarizability are maxima in the $z$-direction is evidenced for charge transfer axis (along the $z$-direction). On the other hand, for M06-2X, the first-order hyperpolarizability is found to be maximum along a direction between $x$ and $y$ directions $\left(\beta_{x x y}=9.262 \times 10^{-30} \mathrm{esu}\right)$. This evidence of maximum dipole moment in $y$-component and polarizability along $x$-component confirms the charge transfer axis (along $x-y$ directions). The total values of the first-order 
hyperpolarizability, $\beta_{\text {tot }}=19.23 \times 10^{-30}$ esu (B3LYP functional) and $\beta_{\text {tot }}=11.85 \times 10^{-30}$ esu (M06-2X functional), are 55 and 34 times greater than that of urea $\left(3.48 \times 10^{-31}\right.$ esu $)$ [55]. Similarly, second-order hyperpolarizability $(\gamma)$ parameter is related to third-order nonlinearity where the optical frequency is dominated by higher order. Hence, it contributes to two-photon resonance. The second-order hyperpolarizability $(\gamma)$ for DMPMS is found to be $-37.9 \times 10^{-40} \mathrm{esu}$ (in B3LYP functional) and $-25.77 \times 10^{-40}$ esu (in M06-2X functional). According to quantum optics, the negative sign indicates the self-defocusing effect and negative $\gamma$ materials are more sensitive to the structural change [56]. In the present investigation, nonlinear optical parameters are obtained from both B3LYP and M06-2X functional approach and the results are compared. According to Shabbir Muhammad et al. [52], the values obtained from the B3LYP are overestimated parameters as compared to M06-2X. Hence, the results obtained from M06-2X are more appropriate than B3LYP functional method.

\subsection{Third-order nonlinear optical properties}

The study on underlying mechanism related to nonlinear optical susceptibility gains attention to acquire knowledge. To study third-order nonlinear optical properties, Sheik Bahae et al. developed a technique called Z-scan, which is effective and standard [57, 58]. In Z-scan measurement, the experimental setup has a Q-switched Nd:YAG laser (Quanta-Ray INDI, Spectra Physics) with second harmonic wavelength of $532 \mathrm{~nm}$ and laser pulse width of $6 \mathrm{~ns}$. In the present study, a low repetition rate of $10 \mathrm{~Hz}$ is used and experiment is performed at single shot operation mode to avoid the cumulative thermal optical nonlinear effect. The sample of DMPMS solution in DMF is taken in a $1 \mathrm{~mm}$ quartz cuvette and scanned across the region from the focus through micrometer translating stage $(+Z$ to $-Z$ positions. The input and output laser power are measured using Newport power meter (843-R) for the process of nonlinear optical study. The focusing lens is used to focus the sample with maximum intensity at the focus with a focal length of $12.4 \mathrm{~cm}$ and the calculated Rayleigh range is $2.1 \mathrm{~mm}$. The laser waist at the focus is $19 \mu \mathrm{m}$. During Z-scan measurement, the fundamental $\mathrm{TEM}_{00}$ mode of the Gaussian beam is used. This Gaussian mode will provide significant nonlinear optical properties from the Z-scan method. The equation for nonlinear transmittance for open aperture $\mathrm{Z}$ scan data, fitted with two-photon absorption (TPA) model, is given by

$$
T(z)=1-\frac{\beta I_{o} L_{\mathrm{eff}}}{2 \sqrt{2}\left(1+\frac{z^{2}}{z_{0}^{2}}\right)},
$$

where $\beta$ is the nonlinear absorption co-efficient dependent on two-photon absorption, $I_{o}$ the peak irradiance ( $\left.I_{o}=4.116 \mathrm{GW} / \mathrm{cm}^{2}\right)$ and $L_{\text {eff }}$ the effective thickness $\left(L_{\text {eff }}=0.93 \mathrm{~mm}\right)$.

The above TPA model is fitted with normalized open aperture Z-scan data, which can be used to extract the parameter of the nonlinear absorption coefficient $(\beta)$. This $\beta$ is adequately favorable to select optical limiting materials. The chalcone derivatives have proved to be good for their $\pi$-conjugation nature. The organic materials are having various kinds of nonlinear optical absorption behavior like free carrier absorption, TPA, and excited-state absorption (ESA) [59]. Free carrier mechanism is the origin of NLA since DMPMS is dielectric material, it shows high band gap value; hence, the free carrier has been excluded from the consideration. The theoretical fit (TPA model) with open aperture Z-scan data confirms that nonlinearity involved by two-photon absorption.

In general, when a material interacts with a high intensity laser beam, the material has saturable absorption (SA) or reverse saturable absorption (RSA) behavior, which depends on the absorptive mechanism of the materials. The material with RSA behavior shows ultra-fast response time as compared to SA. Figure 13 shows open aperture curve in the nanosecond regime has reverse saturable absorption behavior and value of $\beta$ is found to be $28.3 \times 10^{-12} \mathrm{~m} / \mathrm{W}$ at 4.116 $\mathrm{GW} / \mathrm{cm}^{2}$. It is known that NLA co-efficient $(\beta)$ depends on the number of absorptive center in the unit volume $\left(N_{0}\right)$ and the two-photon absorption coefficient $\left(\sigma_{\mathrm{TPA}}\right)$ takes the form $\beta=\sigma_{\mathrm{TPA}} N_{0}$.

Similarly, TPA cross-section $\left(\sigma_{\mathrm{TPA}}{ }^{\prime}\right)$ is given as follows $\sigma_{\mathrm{TPA}}{ }^{\prime}=\sigma_{2} h v$,

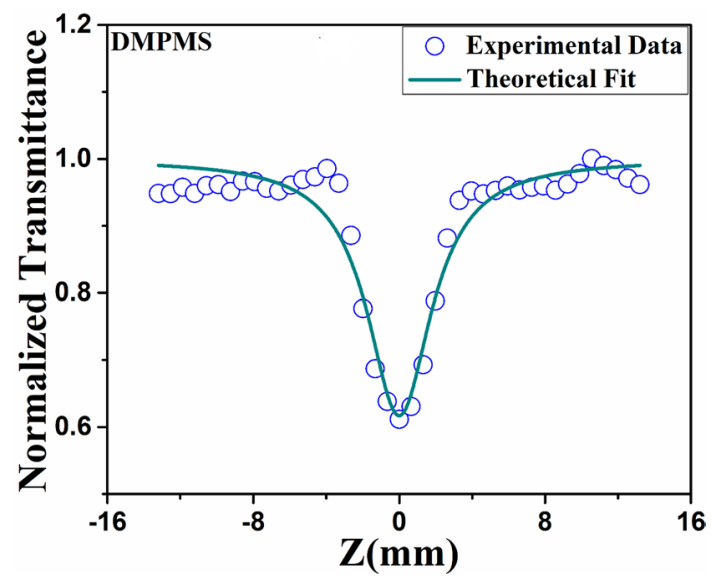

Fig. 13 Nonlinear absorption curve of DMPMS 
where $\sigma_{\mathrm{TPA}}{ }^{\prime}$ is in $\mathrm{cm}^{4} \mathrm{~s} /$ photon and $h v$ is the energy of the incident laser pulse.

The $\sigma_{\mathrm{TPA}}$ and $\sigma_{\mathrm{TPA}}{ }^{\prime}$ are calculated from the above equation and the obtained values are $9.4 \times 10^{-19} \mathrm{~cm}^{4} / \mathrm{GW}$ and $3.5 \times 10^{-46} \mathrm{~cm}^{4} \mathrm{~s} /$ photon, respectively. The $\sigma_{\mathrm{TPA}}$ commonly represented in terms of GM $\left(1 \mathrm{GM}=10^{-50} \mathrm{~cm}^{4} \mathrm{~s} /\right.$ photon $)$ is in good agreement with the values reported in the literature [60].

The sign and magnitude of third-order nonlinear refraction are measured simultaneously from the closed aperture $Z$-scan technique. Here, an aperture is placed in front of the detector and sample is moved from $+\mathrm{Z}$ to $-\mathrm{Z}$ position. The nonlinear refraction data were collected in the presence of an aperture. However, to obtain pure nonlinear refraction, closed aperture data are divided with open aperture (absorption) data. The peak-valley behavior of the nonlinear refraction curve for DMPMS is shown in Fig. 14. The on-axis peak intensity is $4.116 \mathrm{GW} / \mathrm{cm}^{2}$ and this characteristic of the curve is due to the self-defocusing effect.

The induced phase distortion $\left(\Delta \varphi_{0}\right)$, which is related to normalized transmittance between the peak and valley $\left(\Delta T_{\mathrm{pv}}\right)$, is represented accordingly by the Sheik-Bahae relation [61].

$\Delta T_{P V}=0.406(1-S)^{0.25}\left|\Delta \varphi_{0}\right|$

where $S$ is the aperture transmittance $(S=50 \%)$.

The nonlinear refraction curve is fitted in the well-established formula, and the nonlinear transmittance is given by,

$T(Z)=1-\frac{4 X \Delta \varphi_{0}}{\left(X^{2}+9\right)\left(X^{2}+1\right)}$,

where $X=Z / Z_{0}$ and $\Delta \varphi_{0}$ is the nonlinear phase shift $\left(\Delta \varphi_{0}\right.$ $=2.04)$.

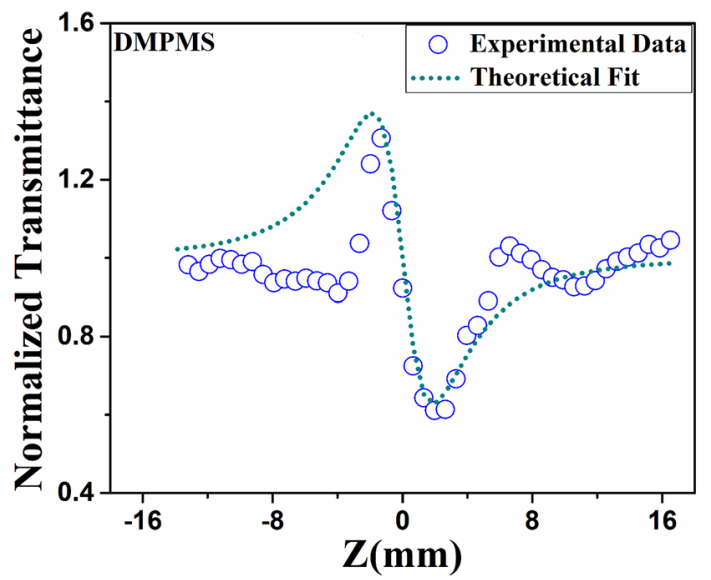

Fig. 14 Nonlinear refraction curve of DMPMS

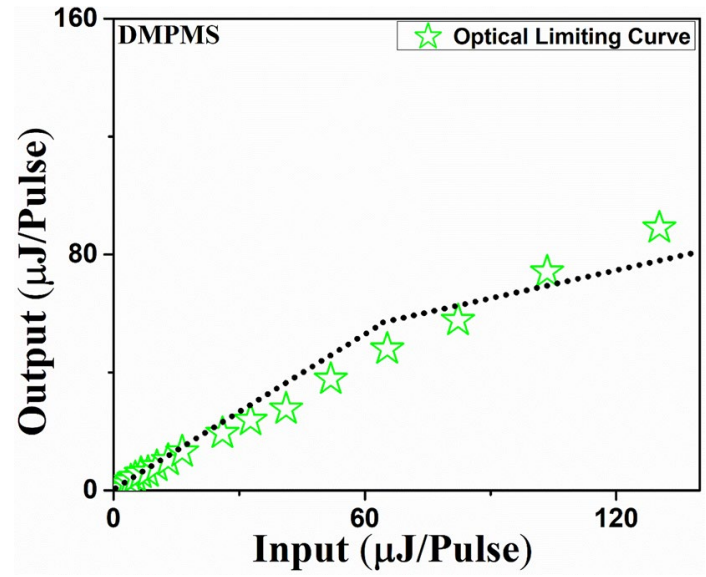

Fig. 15 Optical limiting behavior of DMPMS

The nonlinear refractive index $(\gamma)$ is calculated by knowing the value of $\Delta \varphi_{0}\left(\Delta \varphi_{0}=k n_{2} I_{0} L_{\text {eff }}\right)$ and $\gamma$ becomes $\frac{\Delta \varphi_{0} \lambda}{2 \pi L_{\text {eff }} I_{0}}$ $=4.53 \times 10^{-18} \mathrm{~m}^{2} / \mathrm{W}$ (where $k=\frac{2 \pi}{\lambda}$ ).

The nonlinear refraction coefficient is calculated from the following relations

$n_{2}(\mathrm{esu})=c n_{0} / 40 \pi \gamma \mathrm{m}^{2} / \mathrm{W}$.

The value of $n_{2}$ is found to be $1.75 \times 10^{-11} \mathrm{esu}$.

Similarly, third-order nonlinear optical susceptibility is represented by

$\chi^{(3)}=\sqrt{\left(\operatorname{Re}\left(\chi^{(3)}\right)\right)^{2}+\left(\operatorname{Im}\left(\chi^{(3)}\right)\right)^{2}}$,

where $\operatorname{Im}\left(\chi^{(3)}\right)=\frac{10^{-2} \times n_{0}{ }^{2} C^{2} \varepsilon_{0} \beta \lambda}{4 \pi^{2}}$ and $\operatorname{Re}\left(\chi^{(3)}\right)=\frac{10^{-4} \times n_{0}{ }^{2} C^{2} \varepsilon_{0} \gamma}{\pi}$.

The value of $\operatorname{Im}\left(\chi^{\left.4 \pi^{2}\right)}\right)$ and $\operatorname{Re}\left(\chi^{(3)}\right)$ is found ${ }^{\pi}$ to be $0.793 \times 10^{-12}$ esu and $2.99 \times 10^{-12}$ esu, respectively.

The nonlinear refractive index $(\gamma)$ and NLA coefficient $(\beta)$ in real and imaginary part will validate the third-order nonlinear optical susceptibility $\left(\chi^{(3)}\right)$ parameter. The value of $\chi^{(3)}$ is $3.1 \times 10^{-12} \mathrm{esu}$. The third-order susceptibility is reasonably larger than terphenyl derivatives [62]. The reported third-order nonlinear optical parameters are in good agreement with other chalcone derivatives [12, 21, 63, 64].

\subsection{Optical limiting study}

The optical limiting study is performed by placing a sample in the fixed position and output optical power values are collected for different input power values. The input and output power are recorded using Newport power meter (843-R). The principle of optical limiting is to stabilize the output intensity beyond a particular input intensity. That means higher input intensity will lead only constant output power. The experimental method consists of Nd:YAG laser (Quanta-Ray INDI, Spectra Physics) beam of $532 \mathrm{~nm}$, 
focused on the solution of the sample, with a focal length of $12.4 \mathrm{~cm}$. The sample is fixed at the position where the light intensity is maximum at the sample. Further, input intensity is steadily increased and output intensity is collected. In general, the large nonlinear absorption co-efficient materials show a good optical limiting response. However, in the present study, $\beta$ has a smaller value. Figure 15 shows the optical limiting curve for DMPMS. The output energy (transmittance energy) follows Beer's law at very low-intensity region until $51 \mu \mathrm{J}$. After threshold energy (about $65 \mu \mathrm{J}$ ), the average output clamped energy is found to be $59.5 \mu \mathrm{J}$. The optical limiting response is due to two-photon absorption mechanism and the third-order optical nonlinearity is obtained from the delocalized electron [5].

\subsection{Structure-property relation}

The optical nonlinearity in the organic materials is due to delocalization of $\pi$-electron. The molecule can be designed by the substitution of various functional groups (donors/ acceptors) in the aromatic ring. The molecule (DMPMS) has two donor electrons (methoxy group) in meta and para positions of the aromatic ring understudy, and the carbonyl group acts as an electron acceptor. On the other hand, the sulfonyl group is an even stronger electron-withdrawing group than the carbonyl group. The methyl group creates a charge transfer process with the central group (sulfonyl/ carbonyl group). Charge transfer takes place through the delocalized electron along a $\pi$-conjugation bridge, which contributes to the large electron density in the molecule. Hence, nonlinear optical effect may get enhanced [65, 66].

According to Liu et al. [25], if the molecules have elongated $\pi$-conjugation then the maximum absorbance peak is shifted to shorter wavelength. DMPMS shows maximum absorbance at $308 \mathrm{~nm}$ as compared to DMP3FP [1-(3,4-dimethoxyphenyl)-3-(3-fluorophenyl) prop-2-en-1one] ( $\approx 370$ to $390 \mathrm{~nm}$ ) [19]. The effect of $\pi$-conjugation length is the presence of strong electron donor (methoxy) group in the molecule. Therefore, the elongation of $\pi$-conjugation length leads to effective charge transfer process. In DMPMS, during intermolecular interactions, the molecules are likely to have a mismatch plane with the other molecule, due to which a stacking fault has appeared in crystal packing. The presence of stacking fault led by point defects exhibits the emission in blue region. On the other hand, stereogenic carbon atom creates defect states in the crystal lattice, which appeared in the green region [39]. The defect states obtained from the stacking fault and Stereogenic carbon atom can be in tune with various electron donor/acceptor substitutions based on the requirement. Further, in electronic polarizability, the contribution of molecular polarizability at particular direction will affect the electronic polarizability in the bulk system. In
DMPMS, charge transfer axis is not in a particular direction but the maximum polarizability is found for $x$-component $\left(\alpha_{x x}=72.36 \times 10^{-24} \mathrm{esu}\right)$ as compared to other components. There is no significant change observed in polarizability parameter at molecular level; hence, dielectric constant is not affected and shows low value of 4.42 at $1 \mathrm{MHz}$.

The methoxy-based chalcone derivatives have good thermal stability and high laser damage threshold value as compared to other substitutional groups $\left(-\mathrm{Cl},-\mathrm{Br},-\mathrm{F}, \mathrm{NO}_{2}\right.$ and $-\mathrm{Me})$ in the aromatic ring. In our previous study, tosyloxy (aldehyde)- and methoxy (ketone)-based chalcone derivative (4MPMS) is reported [24]. In that, only one methoxy group is taken in a para position, the thermal stability and laser damage threshold value of the crystal is found to be $158{ }^{\circ} \mathrm{C}$ and $6.93 \mathrm{GW} / \mathrm{cm}^{2}$. In DMPMS, the two-methoxy groups in 3, 4 (meta and para) positions of the aromatic ring are chosen. The thermal stability of the crystal gets reduced to $139.7^{\circ} \mathrm{C}$ and laser damage threshold value is increased, which is about $12 \mathrm{GW} / \mathrm{cm}^{2}$. It is noteworthy that the small change in the structure will give a large impact on properties at the macroscopic level. Moreover, the molecule (DMPMS) has both $\mathrm{C}-\mathrm{H} \cdots \mathrm{O}$ and $\mathrm{C}-\mathrm{H} \cdots \pi$ intermolecular interactions, which stabilize the crystal packing. In 4MPMS, crystal packing is stabilized by only $\mathrm{C}-\mathrm{H} \cdots \mathrm{O}$ interactions. In general, The $\mathrm{C}-\mathrm{H} \cdots \pi$ interactions are more effective than $\mathrm{C}-\mathrm{H} \cdots \mathrm{O}$ interaction in terms of charge transfer process and stability of the crystal packing [67]. As a result, the variation in thermal stability and LDT value is observed.

The nonlinear optical properties depend on several structural factors such as molecular planarity, charge transfer axes, conjugation length, and effect of intermolecular interactions [34]. DMPMS molecule shows elongated conjugation length with effective $\mathrm{C}-\mathrm{H} \cdots \pi$ intermolecular interactions but unfortunately, the molecule belongs to non-planar conformation with twisted structure. This is due to steric hindrance caused by methoxy groups in the molecule, which reduces second-order hyperpolarizability value [46]. Moreover, nonlinear refraction and third-order nonlinear optical susceptibility $\left(\chi^{(3)}=3.1 \times 10^{-12} \mathrm{esu}\right)$ are greatly affected as compared to 4MPMS. Unfortunately, nonlinear optical absorption co-efficient value $\left(28.3 \times 10^{-12} \mathrm{esu}\right)$ is not much affected and contributes to pure two-photon absorption. The two-photon absorption co-efficient is $9.4 \times 10^{-19} \mathrm{~cm}^{4} / \mathrm{GW}$. Furthermore, these molecules can be tuned with multiple methoxy groups in meta/ortho/para positions to increase the molecular planarity and high nonlinear optical response [18]. The high planar conformation with reasonable dipole moment value likely has made it to align with head-tail fashion arrangement. The modification of aforementioned structure is required in the field of nonlinear optics. 


\section{Conclusions}

Nonlinear optical single crystal (DMPMS) has been achieved from solvent combination (acetone and ethanol) using simple and cost-effective technique. The quality of the material, purity, and functional groups were assessed from spectroscopic techniques. Single-crystal XRD reveals that $\mathrm{C}-\mathrm{H} \cdots \pi$ intermolecular interactions dominate over $\mathrm{C}-\mathrm{H} \cdots \mathrm{O}$ interactions, which leads to effective charge transfer process. The lattice parameters obtained from single-crystal XRD are in good agreement with powder XRD result. In the linear optical properties, maximum absorbance peak at $308 \mathrm{~nm}$ confirms that molecule has elongated $\pi$-conjugation system. Moreover, the dominant peaks in the blue region are due to stacking fault, which is originated from molecular crystal packing. The melting point of the DMPMS crystal shows reasonably high value $\left(139.7^{\circ} \mathrm{C}\right)$ due to presence of strong methoxy group. The electronic polarizability parameter assessed from the Penn model $\left(\alpha=6.11 \times 10^{-23} \mathrm{~cm}^{3}\right)$ is almost equal to the Clausius-Mossotti relation $\left(\alpha=6.74 \times 10^{-23} \mathrm{~cm}^{3}\right)$. In theoretical estimations, electronic polarizability parameters obtained from B3LYP functional is overestimated as compared to M06-2X functional. From M06-2X hybrid functional, the maximum dipole moment is along $y$-component ( $\mu_{y}=3.5228$ Debye $)$ and the maximum electronic polarizability is found along $x$-direction $\left(\alpha_{x x}=72.36 \times 10^{-24} \mathrm{esu}\right)$. This evidences the charge transfer axis along $x-y$ directions. It is noteworthy that DMPMS crystal shows high laser damage threshold, about $12 \mathrm{GW} /$ $\mathrm{cm}^{2}$, due to $\mathrm{C}-\mathrm{H} \cdots \pi$ contribution. The second-order hyperpolarizability $\left(-25.77 \times 10^{-40} \mathrm{esu}-\mathrm{M} 06-2 \mathrm{X}\right.$ functional $)$ shows reasonably small value due to steric hindrance caused from multiple methoxy groups. In addition, third-order susceptibility is $3.1 \times 10^{-12} \mathrm{esu}$. Similarly, nonlinear absorption co-efficient value is found to be $28.3 \times 10^{-12} \mathrm{~m} / \mathrm{W}$ at 4.116 $\mathrm{GW} / \mathrm{cm}^{2}$. The optical nonlinearity in the material is due to two-photon absorption, where the transitions take place between two fictitious energy levels. The calculated value of two-photon absorption coefficient is $9.4 \times 10^{-19} \mathrm{~cm}^{4} / \mathrm{GW}$. From optical limiting study, limiting threshold and average output clamping energy are found to be $65 \mu \mathrm{J}$ and $59.5 \mu \mathrm{J}$, respectively. The good crystallinity, better thermal stability, high laser damage threshold value, and good nonlinear response make the material better candidate for microelectronic/optical limiting device applications.

Acknowledgements Open access funding provided by Manipal Academy of Higher Education, Manipal. Authors are thankful to SAIF, IIT Madras (FT-Raman) for characterization facility at subsidized rate. Authors are thankful to Dr. Poonam Tandon and Mr. Rajesh Kumar, University of Lucknow, Lucknow for theoretical studies. VP sincerely thanks MAHE, Manipal for providing fellowship. V. Upadhyaya is grateful to Dr. Subrahmanya K. Bhat for his help in discussions.

\section{Compliance with ethical standards}

Conflict of interest Authors declare that there is no conflict of interest in the present manuscript.

Open Access This article is licensed under a Creative Commons Attribution 4.0 International License, which permits use, sharing, adaptation, distribution and reproduction in any medium or format, as long as you give appropriate credit to the original author(s) and the source, provide a link to the Creative Commons licence, and indicate if changes were made. The images or other third party material in this article are included in the article's Creative Commons licence, unless indicated otherwise in a credit line to the material. If material is not included in the article's Creative Commons licence and your intended use is not permitted by statutory regulation or exceeds the permitted use, you will need to obtain permission directly from the copyright holder. To view a copy of this licence, visit http://creativecommons.org/licenses/by/4.0/.

\section{References}

1. Z. Chai, X. Hu, F. Wang et al., Ultrafast all-optical switching. Adv. Opt. Mater. 5, 1600665 (2017)

2. R.L. Gieseking, S. Mukhopadhyay, C. Risko et al., 25th anniversary article: design of polymethine dyes for all-optical switching applications: Guidance from theoretical and computational studies. Adv. Mater. 26, 68-84 (2014)

3. F. Wang, X. Feng, C.H. Oh, Optical bistability and multistability via quantum coherence in chiral molecules. Opt. Express 24, 13702 (2016)

4. G. Zhao, F. Zhang, Y. Wu et al., One-step exfoliation and hydroxylation of boron nitride nanosheets with enhanced optical limiting performance. Adv. Opt. Mater 4, 141-146 (2016)

5. D. Dini, J.F. Calvete, M. Hanack, Nonlinear optical materials for the smart filtering of optical radiation. Chem. Rev. 116, 13043 13233 (2016)

6. D.N. Beratan, K. Clays, M.J. Therien, Large hyperpolarizabilities at telecommunication-relevant wavelengths in donor-acceptordonor nonlinear optical chromophores. ACS Cent. Sci. 2, 954-966 (2016)

7. X. Li, Z. Shao, M. Zhu et al., Fundamentals of Optical Computing Technology (Springer, Singapore, 2018), pp. 1-33

8. F. Calegari, A. Trabattoni, A. Palacios et al., Development of high harmonic generation spectroscopy of organic molecules and biomolecules. J. Phys. B 49, 132001 (2016)

9. L. Gu, H. Shi, L. Bian et al., Colour-tunable ultra-long organic phosphorescence of a single-component molecular crystal. Nat. Photonics 13, 406-411 (2019)

10. K. Zheng, S. Han, X. Zeng et al., Rewritable optical memory through high-registry orthogonal upconversion. Adv. Mater. 30, 1801726 (2018)

11. T. Chandra Shekhara Shetty, S. Raghavendra, C.S. Chidan Kumar et al., Crystal structure, Hirshfeld and third-order nonlinear optical properties of 3-(4-dimethylamino)phenyl)-1-(4-methoxyphenyl) prop-2-en-1-one: A potential material for optical limiting applications. Opt. Mater. (Amst) 86, 138-147 (2018)

12. P.S. Patil, S.R. Maidur, M. Shkir et al., Crystal growth and characterization of second- and third-order nonlinear optical Chalcone derivative: (2E)-3-(5-bromo-2-thienyl)-1-(4-nitrophenyl)prop-2en-1-one. J. Appl. Crystallogr 51, 1035-1042 (2018)

13. J.M.F. Custodio, F.G. Santos, W.F. Vaz et al., Molecular structure of hybrid imino-chalcone in the solid state: X-ray diffraction, spectroscopy study and third-order nonlinear optical properties. J. Mol. Struct 1157, 210-221 (2018) 
14. L.M.G. Abegão, F.A. Santos, R.D. Fonseca et al., Chalcone-based molecules: experimental and theoretical studies on the two-photon absorption and molecular first hyperpolarizability. Spectrochim. Acta 227, 117772 (2020)

15. E. Mathew, V.V. Salian, I. Hubert Joe, B. Narayana, Third-order nonlinear optical studies of two novel chalcone derivatives using Z-scan technique and DFT method. Opt. Laser Technol. 120, 105697 (2019)

16. M. Sai Kiran, B. Anand, S. Siva Sankara Sai, G. Nageswara Rao, Second- and third-order nonlinear optical properties of Bis-chalcone derivatives. J. Photochem. Photobiol. A Chem. 290, 38-42 (2014)

17. J.M.F. Custodio, C.N. Perez, C. Valverde et al., Enhanced nonlinear optics properties of a bromine chalcone from a novel polymorph. Chem. Phys. Lett. 738, 136852 (2019)

18. J.S. John, D. Sajan, C. Narayana et al., Theoretical and experimental approach to the investigation of hyperpolarizability and charge transfer characteristics of NLO active $2^{\prime}, 3,4,4^{\prime}, 5$-pentamethoxy chalcone with silver atoms adsorbed. Opt. Mater. (Amst) 84, 409-421 (2018)

19. S. Raghavendra, C.S. Chidan Kumar, T.C.S. Shetty et al., Structure property relationship of a new nonlinear optical organic crystal: 1-(3,4-dimethoxyphenyl)-3-(3-fluorophenyl)prop-2-en1-one for optical power limiting applications. Results Phys. 7, 2550-2556 (2017)

20. S. Raghavendra, K.V. Anil Kumar, T. Chandra Shekhara Shetty, S.M. Dharmaprakash, Structural and optical properties of new organic crystal 1-[4-(methylsulfanyl) phenyl]-3-(2,4,5-trimethoxyphenyl) prop-2-en-1-one for optical limiting applications. J. Mol. Struct 1074, 653-659 (2014)

21. P.S. Patil, S.R. Maidur, S.V. Rao, S.M. Dharmaprakash, Crystalline perfection, third-order nonlinear optical properties and optical limiting studies of 3,4-dimethoxy-4'-methoxychalcone single crystal. Opt. Laser Technol. 81, 70-76 (2016)

22. B. Zhao, Y. Wu, Z.-H. Zhou et al., Theoretical study on the organic molecular second-order hyperpolarizability. Appl. Phys. B Lasers Opt. 70, 601-605 (2000)

23. P.P. Vinaya, A.N. Prabhu, K. Subrahmanya Bhat, V. Upadhyaya, Design, growth and characterization of $D-\pi-A-\pi$-D based efficient nonlinear optical single crystal for optical device applications. J. Phys. Chem. Solids 123, 300-310 (2018)

24. P.P. Vinaya, A.N. Prabhu, K. Subrahmanya Bhat, V. Upadhyaya, Synthesis, growth and characterization of a long-chain $\pi$-conjugation based methoxy chalcone derivative single crystal; a third order nonlinear optical material for optical limiting applications. Opt. Mater. 89, 419-429 (2019)

25. X. Liu, Z. Yang, D. Wang, H. Cao, Molecular structures and second-order nonlinear optical properties of ionic organic crystal materials. Crystals 6, 158 (2016)

26. A. Taher, S. Ponnan, H. Prasad, D.N. Rao, Broadband absorption of nanostructured stainless steel surface fabricated by nanosecond laser irradiation. Nanotechnology 31, 175301 (2020)

27. A.J. Kiran, N.S. Rai, K. Chandrasekharan et al., Substituent dependence of third-order optical nonlinearity in chalcone derivatives. Jpn. J. Appl. Phys. 47, 6312-6316 (2008)

28. P. Yang, J. Xu, J. Ballato et al., Optical limiting in $\mathrm{SrBi}_{2} \mathrm{Ta}_{2} \mathrm{O}_{9}$ and $\mathrm{PbZr}_{\mathrm{x}} \mathrm{Ti}_{1-\mathrm{x}} \mathrm{O}_{3}$ ferroelectric thin films. Appl Phys Lett 80, 3394-3396 (2002)

29. APEX, APEX2, SMART, SAINT, SAINT-Plus: Bruker Program name(s). Bruker AXS Inc., (Madison, Wisconsin, USA. 2012).

30. G.M. Sheldrick, SHELXT: Integrated space-group and crystalstructure determination. Acta Cryst. 71, 3-8 (2015)

31. Sheldrick G M, SHELXL-97 Program automatic solution of Crystal Structures (University of Gottingen: Go ttingen, Germany. 1997).
32. C.F. Macrae, I.J. Bruno, J.A. Chisholm et al., Mercury CSD 2.0: new features for the visualization and investigation of crystal structures. J. Appl. Crystallogr. 41, 466-470 (2008)

33. L.R. Almeida, M.M. Anjos, G.C. Ribeiro et al., Synthesis, structural characterization and computational study of a novel amino chalcone: a potential nonlinear optical material. New J. Chem 41, 1744-1754 (2017)

34. J.M. Cole, J.A.K. Howard, G.J. McIntyre, Influence of hydrogen bonding on the second harmonic generation effect: neutron diffraction study of 4-nitro-4'-methylbenzylidene aniline. Acta Crystallogr. Sect. B Struct. Sci 57, 410-414 (2001)

35. D. Braga, F. Grepioni, L. Maini, S. D’Agostino, Making crystals with a purpose; A journey in crystal engineering at the University of Bologna. IUCrJ 4, 369-379 (2017)

36. A. Altomare, R. Rizzi, N. Corriero, A. Falcicchio, EXPO2013: a kit of tools for phasing crystal structures from powder data. J. Appl. Crystallogr 46, 1231-1235 (2013)

37. S.R. Prabhu, A. Jayarama, K. Chandrasekharan, V. Upadhyaya, Synthesis, growth, structural characterization, Hirshfeld analysis and nonlinear optical studies of a methyl substituted chalcone. J. Mol. Struct 1136, 244-252 (2017)

38. J. Tauc, R. Grigorovici, A. Vance, Optical properties, and electronic structure of amorphous germanium. Phys. Stat. Sol. B 15, 627-637 (1996)

39. O.P. Moreno, F.J.M. Bustamante, M.C. Portillo et al., Photoluminescent green emission band induced by the systematic change of $-\mathrm{CH}_{3},-\mathrm{OCH}_{3}$ and naphthyl groups in chiral imines. Cryst. Growth Des. 18, 660-668 (2018)

40. J. Ramírez-Márquez, O. Portillo-Moreno, R. Palomino-Merino et al., Blue and green emission bands in the enantiopure $(S)-(-$ )-1-[(1-phenyl)- $N$-(biphen-2-yl)methylidene] ethylamine: morphological, structural and optical properties. Optik 185, 331-338 (2019)

41. A. Saeed, I. Sharma, A.A. Akl, Physical and optical properties of a-Ge-Sb-Se-Te bulk and film samples: refractive index and its association with electronic polarizability of thermally evaporated a-Ge 15-x Sb x Se 50 Te 35 thin-films. J Non Cryst Solids 531, $119853(2020)$

42. D.R. Penn, Wave-number-dependent dielectric function of semiconductors. Phys. Rev. 128, 2093 (1962)

43. J.C. Phillips, Ionicity of the chemical bond in crystals. Rev. Mod. Phys 42, 317-356 (1970)

44. R.R. Reddy, Y.N. Ahammed, Relation between energy gap and electronic polarizability of ternary chalcopyrites. Infrared Phys. Technol 37, 505-507 (1996)

45. A. Saeed, Studies on dielectric properties, opto-electrical parameters and electronic polarizability of thermally evaporated amorphous Cd 50 S 50 A x Sex thin films. J. Alloys Compd. 671, $566-578$ (2016)

46. H.J. Ravindra, K. Chandrashekaran, W.T.A. Harrison, S.M. Dharmaprakash, Structure and NLO property relationship in a novel chalcone co-crystal. Appl. Phys. B Lasers Opt. 94, 503-511 (2009)

47. S. Raghavendra, C.S. Chidankumar, A. Jayarama, S.M. Dharmaprakash, 1-[4-(methylsulfanyl) phenyl]-3-(4-nitropshenyl) prop-2-en-1-one: a reverse saturable absorption based optical limiter. Mater. Chem. Phys 149, 487-494 (2015)

48. A.D. Becke, Density-functional thermochemistry. III. The role of exact exchange. J. Chem. Phys. 98, 5648-5652 (1993)

49. G.A. Petersson, A. Bennett, T.G. Tensfeldt, M.A. Al-Laham, W.A. Shirley, J. Mantzaris, A complete basis set model chemistry. I. The total energies of closed-shell atoms and hydrides of the first-row elements. J. Chem. Phys. 89, 2193-2218 (1988)

50. P.J. Stephens, F.J. Devlin, C.F. Chabalowski, M.J. Frisch, Ab Initio calculation of vibrational absorption and circular dichroism 
spectra using density functional force fields. J. Phys. Chem. 98, 11623-11627 (1994)

51. Frisch MJ, Trucks GW, Schlegel HB, Scuseria GE, Robb MA, et al Gaussian 09, Revision A. 02, Gaussian, Inc., (Wallingford CT 2010)

52. S. Muhammad, A.G. Al-Sehemi, A. Irfan, A.R. Chaudhry, Tuning the push-pull configuration for efficient second-order nonlinear optical properties in some chalcone derivatives. J. Mol. Graph. Model 68, 95-105 (2016)

53. T. Sugino, N. Kambe, N. Sonoda et al., Ab initio molecular orbital calculations of the static polarizabilities of xanthone analogues. Chem. Phys. Lett 251, 125-131 (1996)

54. D.A. Kleinman, Nonlinear dielectric polarization in optical media. Phys. Rev 126, 1977-1979 (1962)

55. C. Adant, M. Dupuis, J.L. Bredas, Ab initio study of the nonlinear optical properties of urea: electron correlation and dispersion effects. Int. J. Quantum Chem 56, 497-507 (1995)

56. A. Kumar, R. Kumar, A. Gupta et al., Molecular structure, nonlinear optical studies and spectroscopic analysis of chalcone derivative (2E)-3-[4-(methylsulfanyl) phenyl]-1-(3-bromophenyl) prop2-en-1-one by DFT calculations. J. Mol. Struct. 1150, 166-178 (2017)

57. M. Sheik-Bahae, A.A. Said, T.H. Wei et al., Sensitive measurement of optical nonlinearities using a single beam. IEEE J. Quantum Electron 26, 760-769 (1990)

58. M. Sheik-Bahae, A.A. Said, E.W. Van Stryland, Stryland, Highsensitivity, single-beam $\mathrm{n}_{2}$ measurements. Opt. Lett. 14, 955-957 (1989)

59. F. Li, Y. Song, K. Yang et al., Determination of nonlinear absorption mechanisms using a single pulse width laser. J. Appl. Phys. 82, 2004-2006 (1997)

60. A. Ajami, T.U. Wien, W. Husinsky, R. Liska, N. Pucher, Two-photon absorption cross section measurements of various two-photon initiators for ultrashort laser radiation applying the Z-scan technique. J. Opt. Soc. Am. B 27, 2290-2297 (2010)

61. M. Sheik-Bahae, A.A. Said, D.J. Hagan, M.J. Soileau, E.W. Van Stryland, Nonlinear refraction and optical limiting in thick media. Opt. Eng. 30, 1228-1235 (1991)

62. L. Kamath, K.B. Manjunatha, S. Shettigar et al., Investigation of third-order nonlinear and optical power limiting properties of terphenyl derivatives. Opt. Laser Technol. 56, 425-429 (2014)

63. V. Parol, V. Upadhyaya, G.S. Hegde et al., Structural and optical characterization of novel nitro substituted D- $\pi$-A- $\pi$-A type chalcone single crystal showing second-order and third-order nonlinear optical properties. Phys. B Condens. Matter. 580, 411830 (2020)

64. T.C. Shekhara, C.S.C. Kumar, K.N.G. Patel et al., Optical nonlinearity of D-A-p-D and D-A-p-A type of new chalcones for potential applications in optical limiting and density functional theory studies. J. Mol. Struct. 1143, 131-133 (2017)

65. A. Praveen Menezes, A. Jayarama, S. Weng Ng, Synthesis, crystal growth and characterization of a D- $\pi$-A type novel organic nonlinear optical single crystal. J. Cryst. Growth 402, 130-137 (2014)

66. J. Sun, G. Wang, C. Liu et al., Synthesis of four pyrene-containing chalcone derivatives: achieving excellent third-order nonlinear optical properties by optimizing halopyridines. Opt. Laser Technol 109, 600-607 (2019)

67. P.S. Patil, V.M. Bhumannavar, M.S. Bannur et al., Second harmonic generation in some donor-acceptor substituted chalcone derivatives. J. Cryst. Process Technol 3, 108-117 (2013)

Publisher's Note Springer Nature remains neutral with regard to jurisdictional claims in published maps and institutional affiliations. 